\title{
EVALUATION OF SWITCHGRASS AS A CO-FIRING FUEL IN THE SOUTHEAST
}

\author{
DOE Cooperative Agreement No. DE-FC36-98G010349 \\ EPRI WO\# 4603-05
}

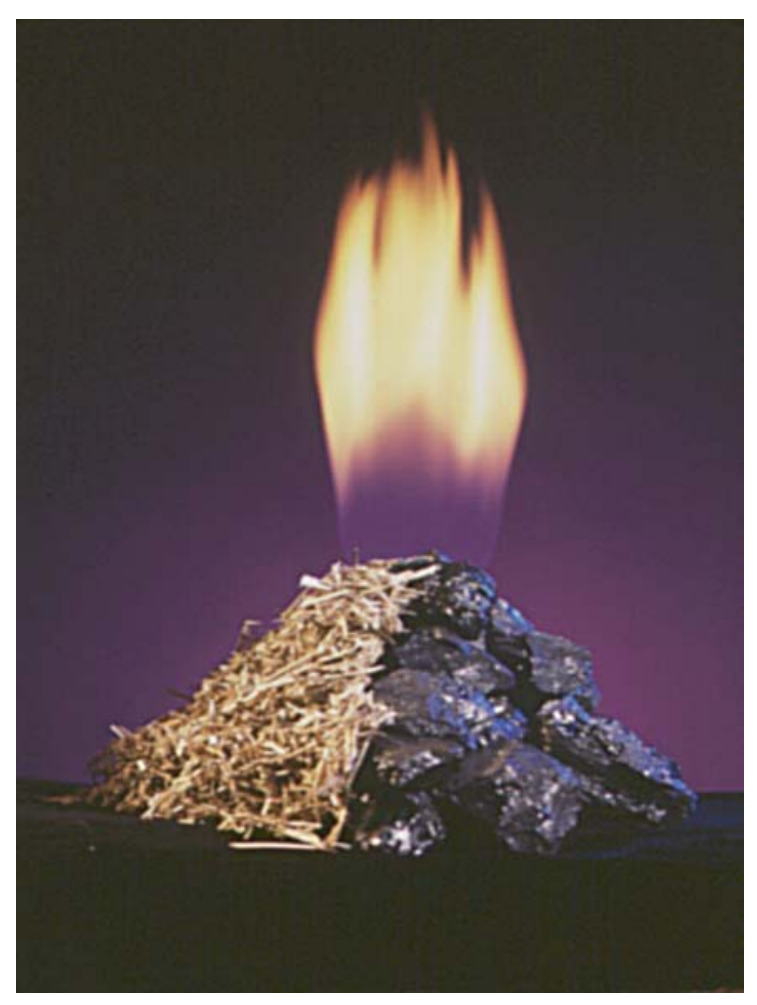

\section{Final Technical Report}

November 2001

\author{
P. Vann Bush \\ SOUTHERN RESEARCH INSTITUTE \\ Birmingham, AL
}

Dr. David I. Bransby

AgteC DEVELOPMENT, LLC.

Auburn, AL
Dr. H. Arlen Smith

Dr. C. Robert Taylor

AGSIM ASSOCIATES

Opelika, AL

Dr. Doug M. Boylan

SOUTHERN COMPANY SERVICES

Birmingham, AL 


\section{TABLE OF CONTENTS}

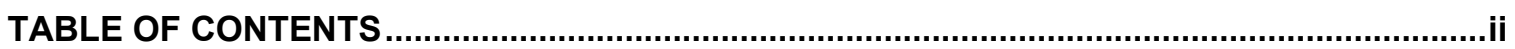

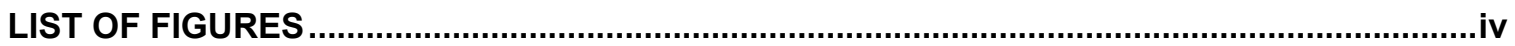

LIST OF TABLES.............................................................................................................

ACKNOWLEDGEMENTS .............................................................................................vi

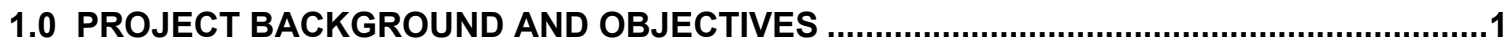

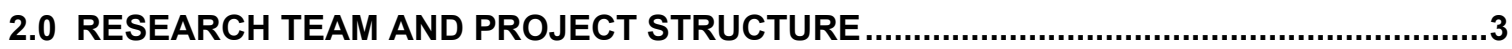

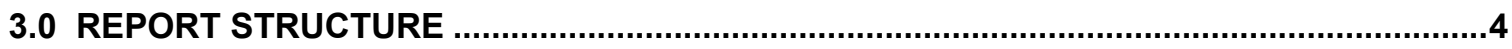

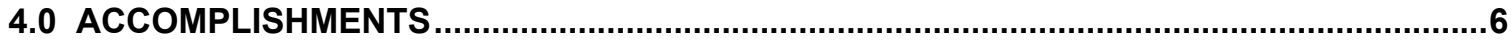

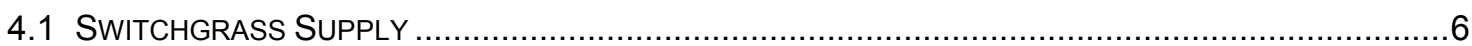

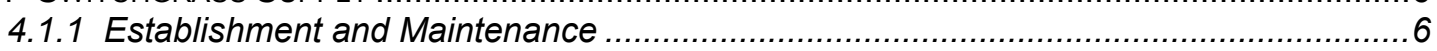

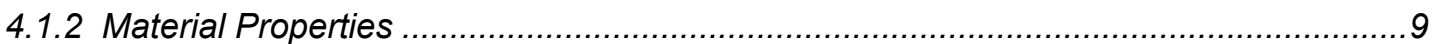

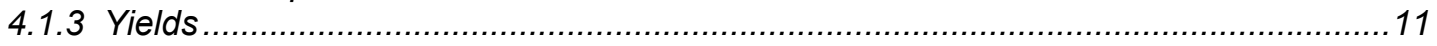

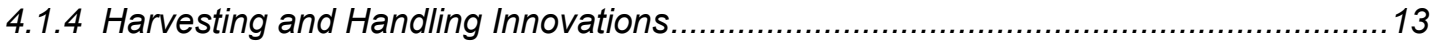

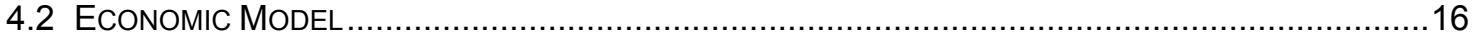

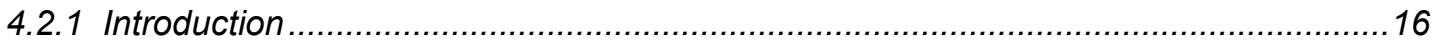

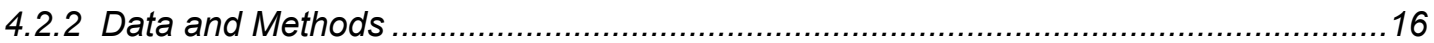

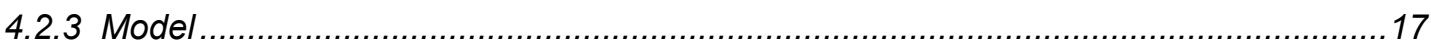

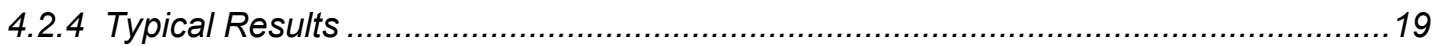

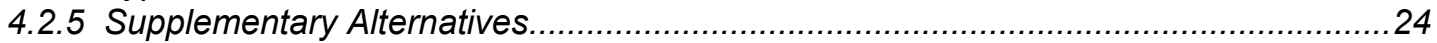

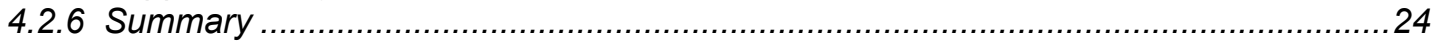

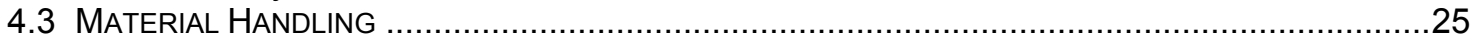

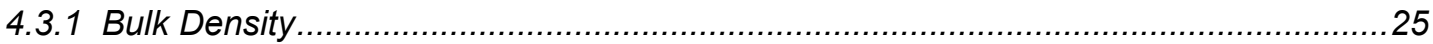

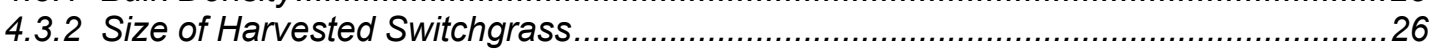

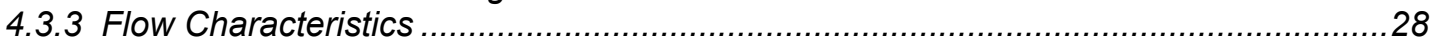

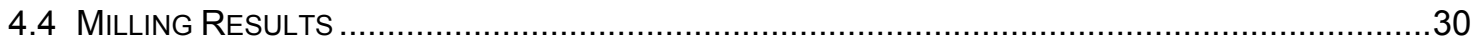

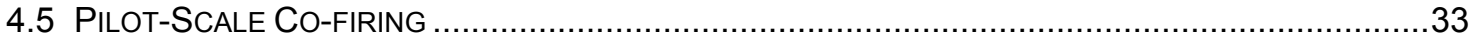

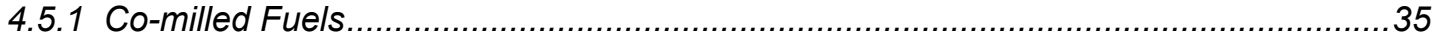

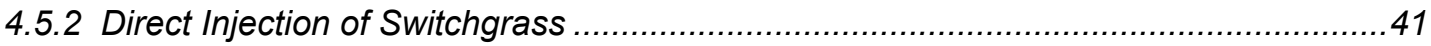

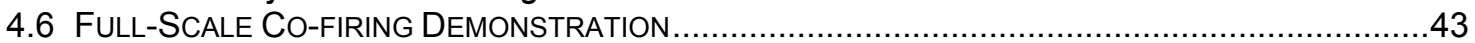

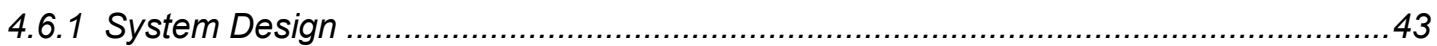

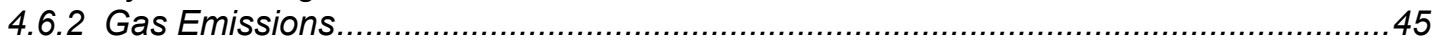

4.6.3 Particulate Control Device Measurements \& Modeling .............................................47

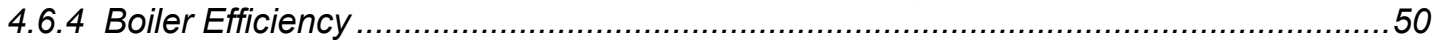

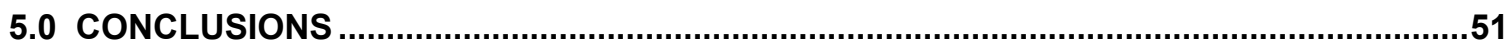

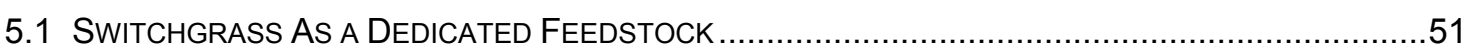

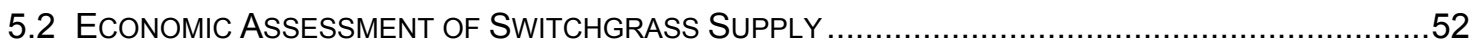

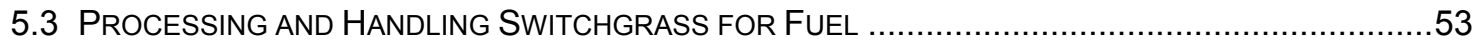

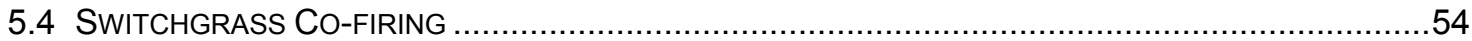

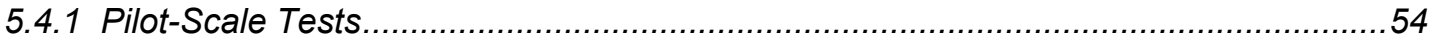

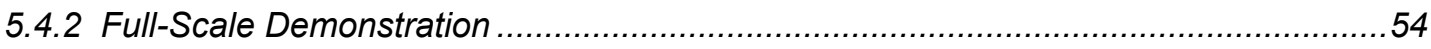

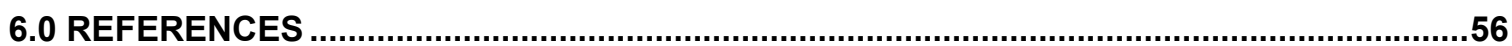




\section{TABLE OF CONTENTS (continued)}

\section{APPENDICES}

A - A PHOTOGRAPHIC SUPPLEMENT FOR SWITCHGRASS PRODUCTION, HARVESTING, AND HANDLING

B - COST OF PRODUSING, HARVESTING, AND DELIVERING SWITCHGRASS AS A BIOMASS POWER FEEDSTOCK: A SPREADSHEET MODEL

C - SOUTHERN RESEARCH INSTITUTE / SOUTHERN COMPANY COMBUSTION RESEARCH FACILITY

D - FULL-SCALE CO-FIRING DEMONSTRATION PARTICULATE CONTROL DEVICE EVALUATION 


\section{LIST OF FIGURES}

Figure $\quad \underline{\text { Page }}$

1. Project Structure and Technical Management Responsibilities............................ 3

2. Early second-year growth of switchgrass at the farm in Lincoln, AL. ..................... 7

3. Established switchgrass at the Winterboro farm site in October 1998. .................. 8

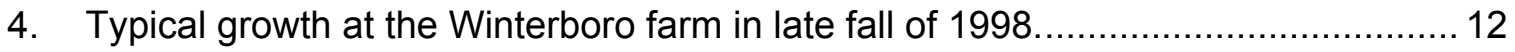

5. Mowing during the 1998 harvest at Winterboro................................................ 14

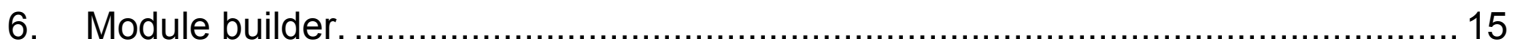

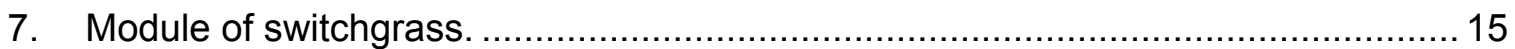

8 Cost per ton of switchgrass delivered depending on yield and transportation option

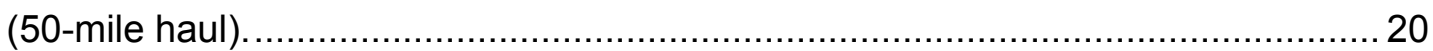

9. Cost per ton of switchgrass delivered depending on transportation option and hauling distance........................................................................................ 21

10. Effect of truck capacity on total cost (50-mile haul)........................................... 22

11. Effect of stand life on total cost of modularized switchgrass. ............................... 23

12. Calculated blend ratios based on heating values for the nominal blends............... 26

13. Size distributions of switchgrass measured with stacked sieves.......................... 27

14. Bulk density versus load of coal and a blend with $5 \%$ switchgrass. ........................ 29

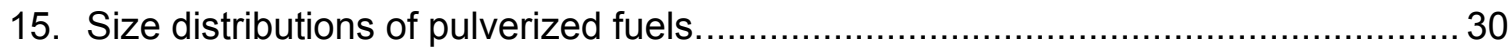

16. Heating value for each of sieve fraction of the pulverized fuel. .............................. 31

17. Calculated blend ratios based on heating values for the nominal blends............... 36

18. NOx concentrations measured when firing Pratt Seam coal alone and with a comilled blend of $90 \%$ coal and $10 \%$ switchgrass (mass basis). ............................ 38

19. NOx concentrations measured when firing Jacobs's Ranch PRB coal alone and with a blend of $90 \%$ coal and $10 \%$ switchgrass (mass basis) ..................................... 39

20. Unburned carbon measured in fly ash after combustion of Pratt Seam bituminous coal and a blend of $90 \%$ coal and $10 \%$ switchgrass (mass basis).

21. NOx concentrations measured when firing Pratt Seam coal alone, with a blend of $90 \%$ coal and $10 \%$ switchgrass (mass basis), and with direct injection of switchgrass equivalent to $10 \%$ of the fuel (mass basis).

22. Schematic illustration of the direct injection system at Plant Gadsden.

23. Coal rollback versus switchgrass rate (adjusted for steam flow) at $3 \% \mathrm{O}_{2}$ for upper and lower burners 45

24. Particle mass distributions at ESP inlet at Plant Gadsden. 


\section{LIST OF TABLES}

$\underline{\text { Table }}$

Page

1. Effect of $\mathrm{N}$ fertilization on ash content, heat of combustion and ash fusion temperature of Alamo switchgrass. 10

2. Effect of cutting frequency and variety on ash content, heat of combustion and ash fusion temperature of switchgrass.

3. Effect of soil type on ash content, heat of combustion and ash fusion temperature of Alamo switchgrass.

4. Comparison of milling performance for bituminous coal and a blended fuel. 32

5. Comparison of milling performance for Powder River Basin coal and a blended fuel. 32

6. Co-firing Test Fuels....

7. Switchgrass ash composition measured after ashing samples at two ignition temperatures. 37

8. Expected and Measured $\mathrm{NO}_{x}$ Reductions at 3.6\% Furnace Exit $\mathrm{O}_{2}$ 39

9. Rollback Data Summary (Values in table are ratios of Rate with co-firing / Rate with coal alone). 46

10. Summary of Mass Concentration Measurements 48 


\section{ACKNOWLEDGEMENTS}

This project was supported by the U.S. Department of Energy under DOE Cooperative Agreement No. DE-FC36-98G010349 and through supplemental funding from the Southeastern Regional Bioenergy Program (SERBEP) and Oak Ridge National Laboratory, by EPRI through Work Order No. 4603-05, and with additional funds contributed by Southern Company Services, Alabama Power Company, and Southern Research Institute. Mr. James Spaeth served as the DOE Contracting Officer's Representative and Ms. Ruth Adams served as the DOE Contracting Officer, both out of the Golden Field Office. Dr. Evan Hughes served as the EPRI Project Manager for this contract. Mr. Rich Bain of NREL and Mr. Mark Downing of ORNL participated as technical advisors to the project.

This project was nurtured, sustained, and executed with the support of a host of organizations and individuals. Dr. Raymond Costello of the DOE Biomass Power Program provided consistent support and encouragement through this project. Mr. Phillip Badger literally provided the seed money for this project as Director of SERBEP. Mr. David Wilson exerted every resource of Wilson Farm to insure development and delivery of a quality switchgrass feedstock, even when faced with uncertain support and drought. Mr. Bill Schaum prepared an exceptional video record of the entire project. Mr. Larry Felix and Mr. Sam O'Neal supervised the pilot-scale testing, which required diligence, persistence, and innovation by the entire Combustion Research Group at Southern Research Institute. Mr. Dave Smith of Southern Research Institute produced many of the chemical analyses that are reported. Mr. Thomas Baxter of Jenike \& Johanson supervised the evaluation of flow properties of switchgrass and coal blends, which played a critical role in the direction of the project. Mr. Wayne Edwards of Alabama Power Company was steadfast in his commitment to demonstrating co-firing at Plant Gadsden. Mr. Bill Zemo of Alabama Power and Mr. Jack Eastis of Southern Company Services made the direct injection test succeed through their tireless efforts. Mr. Wim Marchant directed the particulate measurements at Plant Gadsden and prepared the report of those results. 


\section{EVALUATION OF SWITCHGRASS AS A CO-FIRING FUEL IN THE SOUTHEAST}

\subsection{PROJECT BACKGROUND AND OBJECTIVES}

The "Evaluation of Switchgrass as a Co-Firing Fuel in the Southeast" is a comprehensive project incorporating the highest yielding variety of switchgrass, unique harvesting methods, detailed parametric evaluations in a state-of-the-art combustion research facility, and a full-scale demonstration in a tangentially-fired Alabama Power Company power boiler. These features were incorporated into the project to reduce the technical and economic risk of yielding a practical renewable energy option for the southeastern United States.

There are particular incentives for proving the feasibility of switchgrass as a biomass fuel in the southeastern United States. Even though agriculture is a predominant industry much of the land in this region is under-utilized, marginal farmland. As a result, some of the poorest counties in the nation are located in this region. The yields of switchgrass are substantially higher in the southeastern U.S. than in other regions. Yield, or productivity, is a critical factor in determining the feasibility of biomass fuel. Yields in small research plots in the region averaged $25.8 \mathrm{Mg} / \mathrm{ha}$ (11.5 tons/acre) over the period 1990-1994 (1). Achievable commercial yield in the southeastern U.S. will likely be about 15.7 Mg/ha (7 tons/acre) with currently available varieties.

Use of switchgrass as a supplemental fuel for coal-fired utility boilers could create an enormous market for growers. The Southern Company has 23,000 MW of coal-fired capacity in the southeast. If only $1 \%$ of this capacity was provided by switchgrass instead of coal, 74,500 ha (184,000 acres) of production would be needed. This would generate $1,288,000$ tons of switchgrass which, if valued at $\$ 35 /$ ton, would amount to over $\$ 45$ million.

There are numerous potential advantages for the electric utility industry to use a biomass fuel. Use of biomass will replace fossil fuels with a renewable energy source, decrease the emissions of sulfur (and probably nitrogen) oxides from coal combustion, and decrease net carbon dioxide emissions.

- Switchgrass has almost no sulfur, which means a direct reduction in the emissions of $\mathrm{SO}_{2}$.

- Chemical properties of switchgrass (and most biomass materials) leads to different combustion behavior that has been shown elsewhere to lower NOx emission rates. 
- Biomass crops consume $\mathrm{CO}_{2}$ during their growth, and thus offset any emissions of $\mathrm{CO}_{2}$ when the crops are burned. For a $500 \mathrm{MW}$ unit, replacing $5 \%$ of the fuel energy with biomass would reduce the net emissions of $\mathrm{CO}_{2}$ by about 35 tons/hr.

The price of switchgrass is a principal barrier to its use as a fuel supplement, along with the technical uncertainties of burning switchgrass in plants designed for fossil fuels. At today's prices, there is a significant price penalty for utilities desiring to substitute switchgrass for an equivalent quantity of coal. At a yield of 7 tons/acre the break-even price for switchgrass production has been given as $\$ 21 /$ ton (2). In order for the return for the farmer to be better than would be realized by either pasture or forestry use of the land, harvested switchgrass would cost about \$30/ton, not including transportation costs. This is equivalent to $\$ 2$ per million Btu, assuming a heating value of $7500 \mathrm{Btu} / \mathrm{lb}$ for the switchgrass. Coal prices range from about $\$ 1.20$ to $\$ 1.50$ per million Btu delivered to the user. Obviously, developments are needed to make the use of switchgrass as a substitute fuel economical. The economics of the production, harvesting, transporting, and handling of the switchgrass were evaluated to identify the greatest opportunities to increase efficiency.

Considering the environmental benefits and the potential for renewable energy incentives, this project was designed to establish experimentally the potential of blending switchgrass with coal to fuel electric utility steam boilers in the southeastern United States. Technical issues that had to be addressed included the degree of fuel preparation required for economical and efficient use, the effects of ash properties on deposition on heat transfer surfaces in boilers, and environmental performance. We felt that it was important to evaluate these issues in the Southeast, where switchgrass has a high yield potential and where, to minimize transportation costs, farms could be located near many of the coal-fired plants that the Southern Company operates. 


\subsection{RESEARCH TEAM AND PROJECT STRUCTURE}

The experimental approach we developed for testing the potential of switchgrass as a biomass fuel involved a technical team that included Southern Research Institute, Southern Company Services, AGTEC Development, and AGSIM Associates. Southern Research served as the project coordinator and prime contractor. The project structure and technical management responsibilities for the project are shown below in Figure 1.

\section{Program Technical Coordinator \\ P. Vann Bush, Southern Research Institute}

Task 1. Switchgrass Optimization \& Supply

Leader: Dr. David H. Bransby, AGTEC Development

Agricultural Economist: Dr. C. Robert Taylor, AGSIM Associates

Task 2. Co-Pulverizing Evaluation

Leader: $\quad$ P. Vann Bush, Southern Research Institute

Technical Advisors: Dr. Larry S. Monroe, Southern Research Institute

Dr. Douglas M. Boylan, Southern Company

Task 3. Pilot-Scale Co-Firing Evaluation

Leader: $\quad$ P. Vann Bush, Southern Research Institute

Technical Advisors: Dr. Larry S. Monroe, Southern Research Institute

Dr. Douglas M. Boylan, Southern Company

Task 4. Full-Scale Demonstration of Switchgrass Co-Firing

Leader: Dr. Douglas M. Boylan, Southern Company

Technical Support: P. Vann Bush, Southern Research Institute

Figure 1. Project Structure and Technical Management Responsibilities

The proposed work involved a four-stage approach:

Task 1) Growing and harvesting the switchgrass,

Task 2) Testing the best way to process switchgrass for size reduction,

Task 3) Testing the blended coal and switchgrass fuel in a pilot-scale test furnace, and

Task 4) Full-scale testing of the blended fuel in one of the Southern Company's plants. 
Production and harvesting of sufficient quantities of switchgrass for the proposed testing was primarily the responsibility of AGTEC Development. AGTEC also evaluated the variability in potential slagging and fouling properties of switchgrass ash through chemical analyses of switchgrass samples collected from controlled feedstock management scenarios. This task also involved the study of harvesting, storing, and transporting switchgrass. Results of the study were used to generate an economic model of the process. In this Task a documentary video of the project was also produced under AGTEC's direction.

Finding the best method to produce a switchgrass product for use in a power boiler was the joint responsibility of Southern Research Institute and AGTEC Development. The connection between the harvesting and storage of the fuel with subsequent on-site handling and size reduction was studied. Issues associated with the ability of existing coal handling equipment to cope with the blended fuel was studied in the Southern Company and Southern Research Institute Combustion Research Facility. Southern Research performed controlled, full-scale evaluations of the co-pulverizing of coal and switchgrass. In addition, we engaged Jenike \& Johanson to evaluate the flow characteristics of blends of coal and switchgrass in what turned out to be a very important study of fuel handling options.

The performance of blended coal and switchgrass as a fuel for steam generating boilers was evaluated in the Combustion Research Facility, which includes a test furnace approximately $0.3 \mathrm{MW}(\mathrm{e})$ scale to simulate an electric utility boiler. Tests were performed under well-controlled fuel and combustion conditions. Combustion, slagging and fouling, and emissions properties of the co-fired coal and switchgrass fuel were determined.

Finally, a test burn was performed at Alabama Power's Gadsden Electric Generating Plant, where up to ten percent of the coal was displaced by switchgrass in a $70 \mathrm{MW}$ tangentially-fired unit. The Southern Company had the lead in testing at this scale, with

AGTEC Development arranging for the switchgrass fuel and Southern Research Institute performing some of the emissions measurements.

\subsection{REPORT STRUCTURE}

The final report for this project is a composite product from the separate reports prepared by Task Leaders, as listed in Figure 1 above. In addition to this report, there are four other major documentary products: 
1) Video documentaries of the project - a 23-minute and a 15-minute version - were prepared by Bill Schaum under the supervision of Dr. Bransby.

2) A photographic supplement of the feedstock supply task was prepared by Dr. Bransby (included as Appendix A to this report).

3) A report describing the economic model was prepared by Dr. Taylor and Dr. Smith, and the spreadsheet model was delivered (3). (This report is found in Appendix B.)

4) A separate final report on the full-scale demonstration tests at the Alabama Power Gadsden Steam Plant was prepared by Dr. Doug Boylan et al (4).

In addition to these special reports, there were several presentations and publications produced during the course of this project $(5-10)$. This summary report will incorporate the textual highlights and conclusions from these other reports of project activities, without reproducing their contents. 


\subsection{ACCOMPLISHMENTS}

\subsection{Switchgrass Supply}

\subsubsection{Establishment and Maintenance}

\section{$\underline{\text { 4.1.1.1 Establishment }}$}

Before this project began it was realized that in order to meet the project schedule, there was an urgent need to plant switchgrass so that there would be an established stand to provide feedstock for testing. Thus, planting was actually conducted prior to the official start of the project, funded with $\$ 30,000$ by the Southeastern Regional Bioenergy Program (SERBEP). The Wilson brothers, David and Doug, planted two hundred acres, under the auspices of their farming company, Wilson Farm Inc. The switchgrass was planted at two different sites: 80 acres at Lincoln, $A L$, that is gently sloping and had been previously used for annual cropping, and 120 acres at Winterboro, which has some steep slopes and had previously been in permanent pasture.

Because there was even a delay in confirmation of the SERBEP funding, tillage and planting in 1997 was delayed well beyond optimal dates for these operations. However, a decision was made to take this risk in order to reduce the probability of delaying the project by an entire year. Tillage started in early June, and planting was done in mid- to late July. One feature that was very evident in the tillage operation was the substantially greater amount of tillage needed at the Winterboro site that had previously been in pasture, compared to the Lincoln site that had previously been tilled frequently for annual row cropping. This difference was subsequently incorporated into the economic model.

Even though most 'Alamo' switchgrass seed is produced in Texas, the seed for this project was purchased from Sims Brothers Seed Company of Union Springs, Alabama. This seed had been harvested in fall of 1996, and as is typical, contained a large proportion of dormant seed. (Immediately after harvest, switchgrass seed is often dormant and will not germinate unless it is either strativied - soaked in water to dampen it, and chilled at a temperature slightly above freezing for 2 weeks - or aged in warm temperature storage for several months.) Because of the seed dormancy, and the delay in planting date, the seeding rate used was double that which is normally recommended (10 lb/ac, compared to $5 \mathrm{lb} /$ acre or less). 
Germination, emergence and seedling establishment in late summer and fall of 1997 was very patchy at both sites. Weeds were a serious problem at both sites: at Lincoln, sicklepod, morning glory and other broad leaf weeds were the main problem, while at Winterboro crabgrass and other annual grasses were most prevalent, and extremely dense. The field at Lincoln was sprayed with 2-4D, but no herbicide was applied at Winterboro. Early growth of the stand at the Lincoln site in 1998 is shown in Figure 2. In late fall there were patches at both sites with perfect establishment, and other patches (some of them many acres in size) in which there was no evidence of any switchgrass at all. The Winterboro site is shown in Figure 3 in October 1998 after establishment of the switchgrass stand.

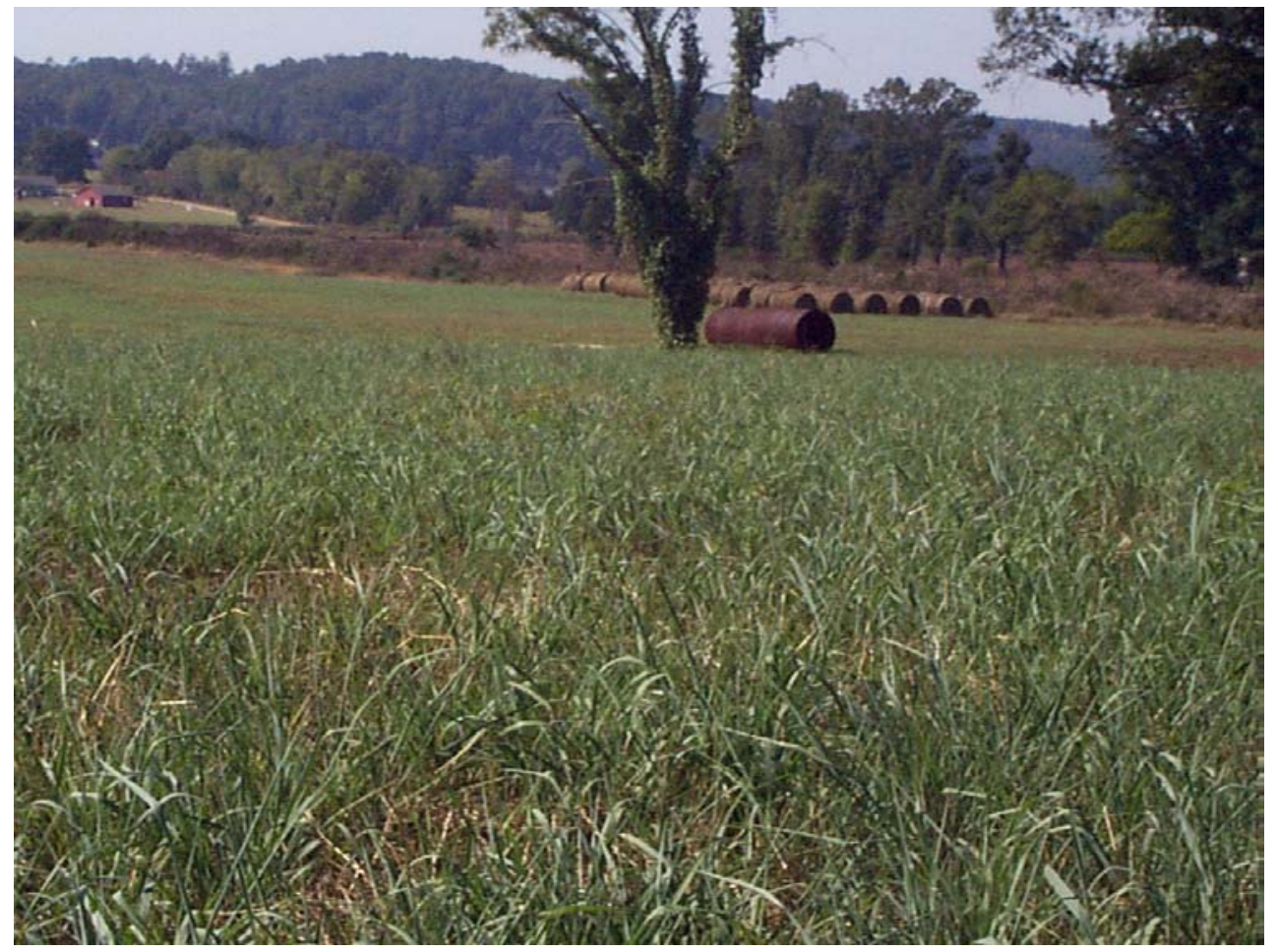

Figure 2. Early second-year growth of switchgrass at the farm in Lincoln, AL. 


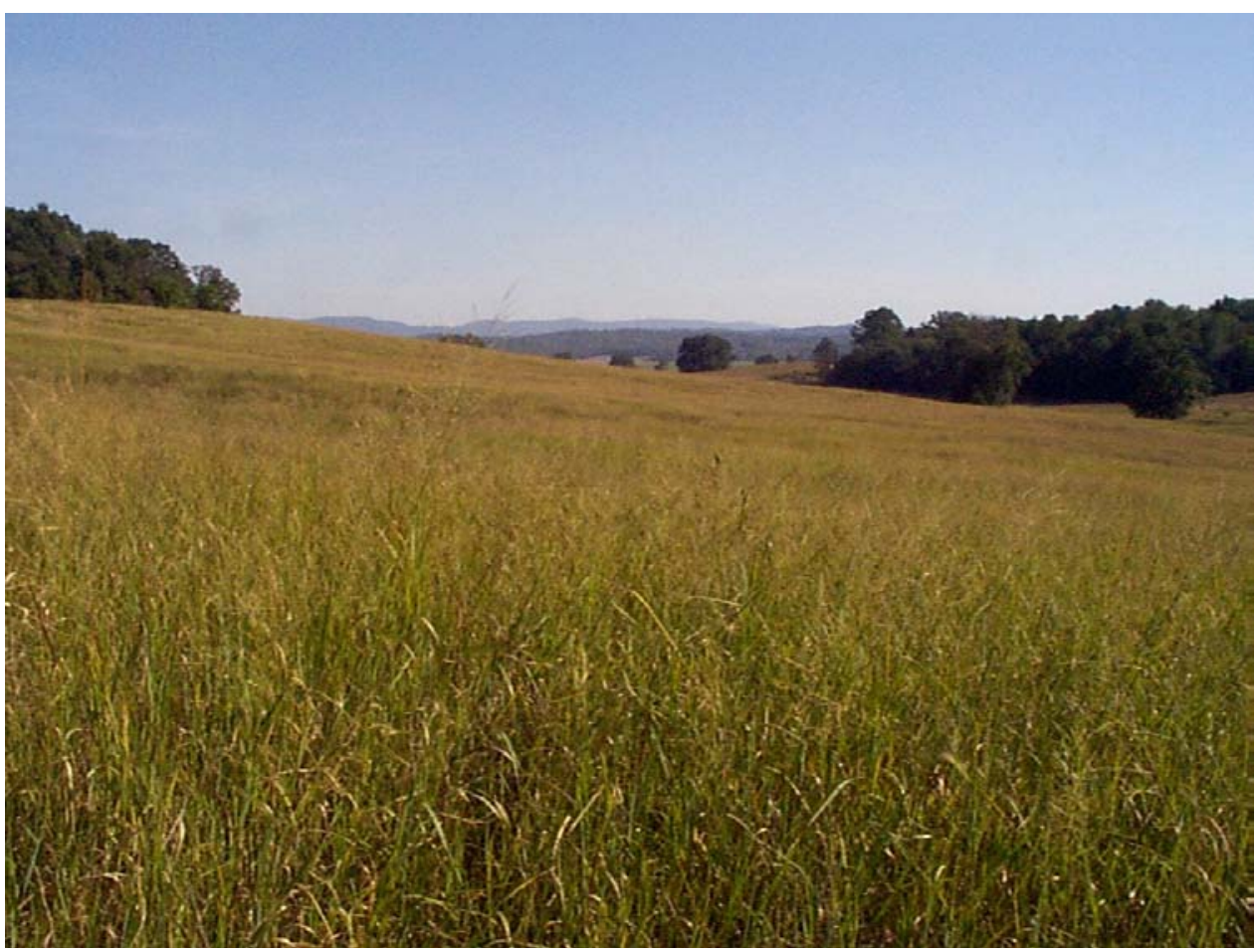

Figure 3. Established switchgrass at the Winterboro farm site in October 1998.

\subsubsection{Maintenance}

In spring of 1998, annual ryegrass posed a serious weed problem, especially at the Winterboro site. Consequently, a decision was made to mow this field to remove the competition. In addition, instead of baling the ryegrass, it was chopped with a large selfpropelled forage chopper leased from a neighboring dairy farm. The chopped ryegrass was very dry when it was put up in a single large stack. However, after several months, this stack caught fire as a result of spontaneous combustion following some rain.

Despite this, three similar stacks of switchgrass put up subsequently, and another at the Auburn University E. V. Smith Research Center, did not catch fire over extended periods of storage without protection from the weather. Consequently, it was concluded that ryegrass has a greater tendency for spontaneous combustion, probably due to higher protein and soluble carbohydrate levels than switchgrass, and therefore, more favorable conditions for microbial growth and respiration which leads to high temperatures and spontaneous combustion.

Following removal of the ryegrass in May, both stands of switchgrass were fertilized with liquid nitrogen, and growth was more vigorous. In addition, it was evident that more germination of switchgrass seed had definitely occurred that spring, because switchgrass seedlings appeared in patches where there had been absolutely no 
evidence of switchgrass the previous fall. Consequently, seed dormancy had delayed some germination until 8 to 9 months after planting.

All 200 acres of switchgrass were harvested in fall of 1998. In 1999, and 2000, switchgrass was fertilized as scheduled with $100 \mathrm{lbN} /$ acre in spring, and harvested in fall.

\subsubsection{Material Properties}

Switchgrass (Panicum virgatum) was selected as the model herbaceous energy crop species for the Oak Ridge National Laboratory's Biofuels Feedstock Development Program (13). This choice was based on many favorable features of switchgrass, including the following: its native origin in North America; genetic diversity; adaptation to an extremely wide range of climates and soil types; capability of high biomass yields with low inputs; effectiveness in carbon sequestration and soil improvement; rapid establishment compared to woody crops; and, value for other uses such as forage for livestock and wildlife habitat. Despite these attributes, an initial assessment (14) suggested that the ash and alkali content of switchgrass was high, thus giving it a strong tendency to slag at temperatures commonly observed under normal furnace operation. A subsequent examination of other research data (15) indicated that the single sample analyzed by Miles et al (14) was probably contaminated with soil, and not representative of most switchgrass biomass. However, data on the combustion properties of switchgrass are still extremely limited. Given that co-firing with coal, and gasification, are among the best near-term opportunities to commercialize switchgrass as an energy crop, the objective of this study was to determine the effect of $\mathrm{N}$ fertilization, cutting frequency, variety and soil type on selected combustion properties of switchgrass.

\subsubsection{Procedure}

Switchgrass samples were clipped by hand from four replicate $10 \times 30 \mathrm{ft}$ plots in existing field experiments in the Auburn University and Alabama Agricultural Experiment Station System. Experiment 1 involved Alamo switchgrass and was located on a sandy coastal plain soil at the E. V. Smith Research Center at Shorter in south-central Alabama, and on a piedmont clay soil at the Piedmont Station at Camp Hill, a little further north. At both locations treatments included fertilization with $\mathrm{N}$ at 0,100 and $200 \mathrm{lb} / \mathrm{acre} / \mathrm{year}$, and plots were cut either once only in September or October, or twice, first in early July and again in September or October. Experiment 2 was located at the E. V. Smith Research Center, but on a sandy loam soil, and it included three switchgrass varieties (Alamo, Cave-in-Rock and Kanlow) cut once or twice per year, as in Experiment 1. 
Samples were dried in a forced air oven at $140^{\circ} \mathrm{F}$ for 48 hours prior to grinding through a 0.25 -inch screen. They were then tested for ash content, heat of combustion and ash fusion temperature at the Alabama Power General Test Laboratory, P. O. Box 2641, Birmingham, AL 35291, and data were analyzed by analysis of variance. To determine the effects of $\mathrm{N}$ fertilization, only the data from the 1-cut treatment in Experiment 1 at the E. V. Smith location were analyzed. Effects of switchgrass variety and cutting frequency were obtained from Experiment 2, using only the material from the second cut of the 2cut treatments. Finally, to determine the effect of soil type, data from the 1-cut treatment on Alamo switchgrass at all three locations were analyzed. All data are reported on a dry basis.

\subsubsection{Results and Discussion}

Heat of combustion was not influenced by $\mathrm{N}$ fertilization, and averaged 8,072 Btu/lb. However, ash content was slightly higher and ash fusion temperature was slightly lower for material that came from unfertilized plots, compared to material from plots that had received either 100 or $200 \mathrm{lb}$ N/acre/year (Table 1). The ash values recorded here (average of $2.41 \%$ ) were considerably lower than the values of over $8 \%$ reported by Miles et al (14) and 4.5-5.8\% reported by McLaughlin et al (15), and the average ash fusion temperature was $8.7 \%$ higher $\left(2,023\right.$ vs. $\left.1,861^{\circ} \mathrm{F}\right)$ than that reported by McLaughlin et al (15).

Table 1. Effect of $\mathbf{N}$ fertilization on ash content, heat of combustion and ash fusion temperature of Alamo switchgrass.

\begin{tabular}{c|c|c|c}
$\begin{array}{c}\text { N Fertilization } \\
(\mathrm{Ib} / \mathrm{ac})\end{array}$ & $\begin{array}{c}\text { Ash Content } \\
(\%)\end{array}$ & $\begin{array}{c}\text { Heat of Combustion } \\
(\mathrm{Btu} / \mathrm{lb})\end{array}$ & $\begin{array}{c}\text { Ash Fusion Temp. } \\
\left({ }^{\circ} \mathrm{F}\right)\end{array}$ \\
\hline 0 & $2.69^{\mathrm{a} *}$ & 7,999 & $1,844^{\mathrm{b}}$ \\
\hline 100 & $2.27^{\mathrm{b}}$ & 8,082 & $2,082^{\mathrm{a}}$ \\
\hline 200 & $2.26^{\mathrm{b}}$ & 8,135 & $2,142^{\mathrm{a}}$ \\
\hline
\end{tabular}

*Values in the same column followed by different letters differ at $\mathrm{P}<0.05$.

In Experiment 2, heat of combustion averaged 8,147 Btu/lb and was not different among switchgrass varieties or cutting frequencies. Ash content was higher $(P<0.01)$ for the 2cut material than for the 1-cut material (on average, $3.89 \%$ and $3.21 \%$, respectively), but did not differ among varieties (Table 2). Ash fusion temperature for Kanlow switchgrass $\left(2,204^{\circ} \mathrm{F}\right)$ was higher than for Alamo $\left(2,089^{\circ} \mathrm{F}\right)$, but these values did not differ from that of Cave-in Rock $\left(2.138{ }^{\circ} \mathrm{F}\right)$. Cutting frequency did not influence ash fusion temperature. 
Table 2. Effect of cutting frequency and variety on ash content, heat of combustion and ash fusion temperature of switchgrass.

\begin{tabular}{l|c|c|c|c}
$\begin{array}{c}\text { Switchgrass } \\
\text { Variety }\end{array}$ & $\begin{array}{c}\text { Number of } \\
\text { cuts/year }\end{array}$ & $\begin{array}{c}\text { Ash Content } \\
(\%)\end{array}$ & $\begin{array}{c}\text { Heat of Combustion } \\
(\mathrm{BTU} / \mathrm{lb})\end{array}$ & $\begin{array}{c}\text { Ash Fusion Temp. } \\
\left({ }^{\circ} \mathrm{F}\right)\end{array}$ \\
\hline \multirow{2}{*}{ Alamo } & 1 & 3.08 & 8,156 & 2,061 \\
\cline { 2 - 5 } & 2 & 4.03 & 8,130 & 2,118 \\
\hline \multirow{2}{*}{ Cave-in-Rock } & 1 & 3.20 & 8,128 & 2,136 \\
\cline { 2 - 5 } & 2 & 3.86 & 8,138 & 2,141 \\
\hline \multirow{2}{*}{ Kanlow } & 1 & 3.37 & 8,189 & 2,144 \\
\cline { 2 - 5 } & 2 & 3.78 & 8,140 & 2,264 \\
\hline
\end{tabular}

Heat of combustion and ash fusion temperature did not differ among soil types.

However, on average, ash content of material from the sandy loam soil was $45 \%$ higher $(P<0.01)$ than that from the sandy and clay soils (Table 3$)$.

Table 3. Effect of soil type on ash content, heat of combustion and ash fusion temperature of Alamo switchgrass.

\begin{tabular}{l|c|c|c} 
Soil Type & $\begin{array}{c}\text { Ash Content } \\
(\%)\end{array}$ & $\begin{array}{c}\text { Heat of Combustion } \\
\text { (BTU/lb) }\end{array}$ & $\begin{array}{c}\text { Ash Fusion Temp. } \\
\left({ }^{\circ} \mathrm{F}\right)\end{array}$ \\
\hline Clay & $1.99^{\mathrm{b} *}$ & 8,175 & 2,034 \\
\hline Sandy & $2.27^{\mathrm{b}}$ & 8,082 & 2,082 \\
\hline Sandy Loam & $3.08^{\mathrm{a}}$ & 8,156 & 2,061 \\
\hline
\end{tabular}

*Values in the same column followed by different letters differ $(P<0.01)$.

\subsubsection{Yields}

Switchgrass yields in this project were disappointing, primarily due to drought. In 1998, yields were only around 2 to 3 dry tons per acre. Rainfall in this season was below the long-term average, but the low yield was mainly due to late planting in 1997, and seed dormancy. Consequently, 1998 would really have to be considered as the establishment year, in which yields are typically only 30 to $40 \%$ of maximum, even if rainfall is good.

The 1999 season can be considered as the second season following, in which yields are typically about $70 \%$ of maximum. However, due to below average rainfall in a second consecutive season, yields were about 3 to 4 dry tons per acre. In 2000 the drought was the worst in over 100 years in many parts of Alabama. At both the E. V. Smith Research 
Center between Auburn and Montgomery and the Tennessee Valley Station near Huntsville, rainfall from March to September, which is the switchgrass growing season, was only $52 \%$ of the long term (30-year) average (17 inches, compared to the long term average of 33 inches). In addition to low rainfall, average temperatures in all three years were 4 to 5 degrees higher than the long-term averages, resulting in higher evaporation rates, compromising the effectiveness of the little rain that did fall, and imposing further stress on plants. Given these extreme weather conditions, and the relative immaturity of the stands, the yields around 4 dry tons/acre achieved in 2000 were indeed remarkable.

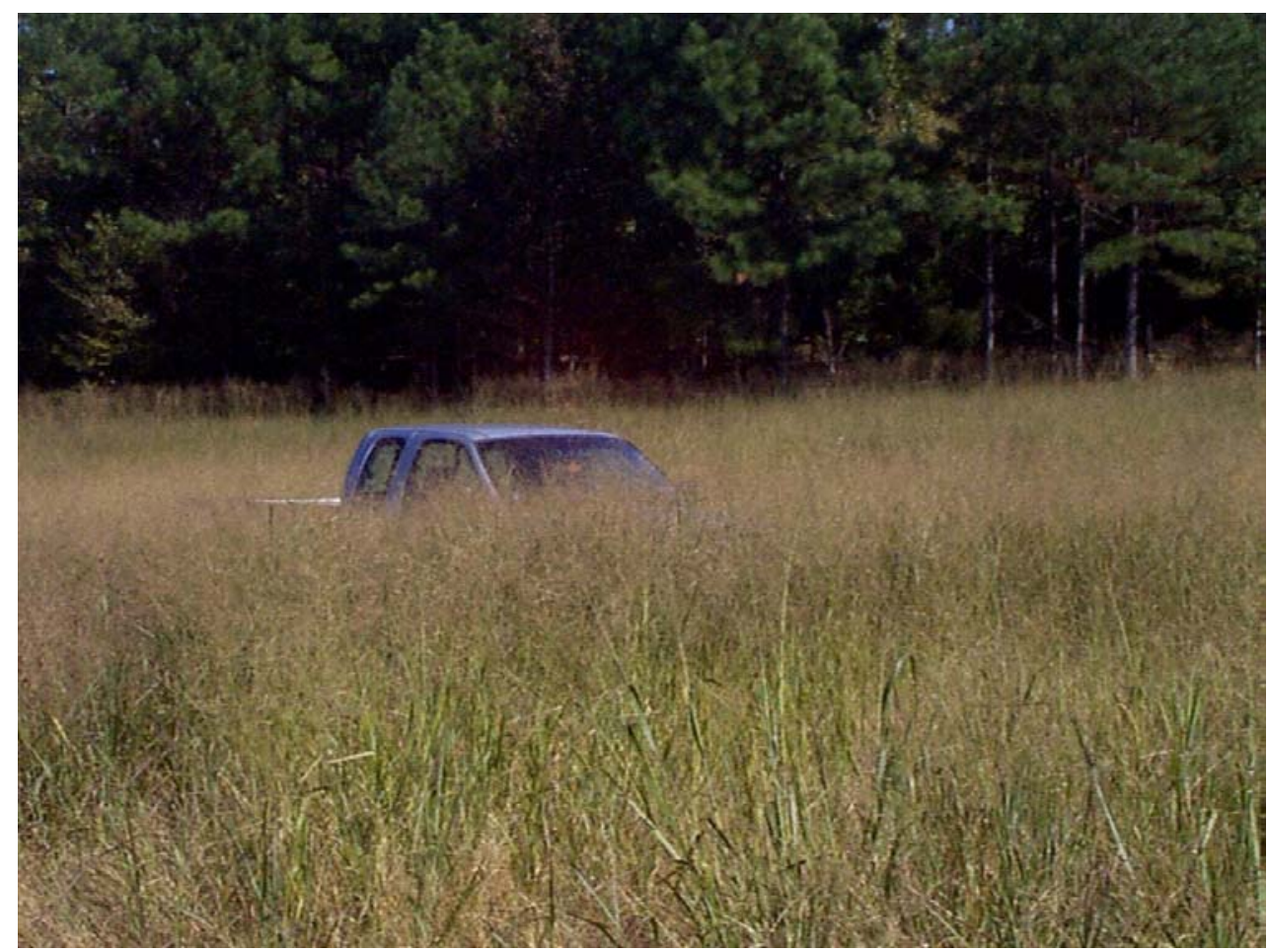

Figure 4. Typical growth at the Winterboro farm in late fall of 1998.

Even though the switchgrass production phase of this project did not continue through 2001, the switchgrass sites were visited at the end of August of this year. Rainfall in 2001 was well above normal, and well distributed throughout the season. Fields were not fertilized at all in spring, but were cut for hay in early July, and cut again in September or October. Based on a bale count at the Lincoln site, estimated yield for the first harvest was about 3.5 tons per acre, and a visual assessment of regrowth suggests that the second harvest should provide at least another 2 tons per acre, for a total of about 5.5 tons per acre. Considering that this was achieved with no fertilization, it is assumed that the target yield of 7 tons per acre would have been achieved in 2001 with the application of $100 \mathrm{lb}$ of nitrogen per acre. 


\subsubsection{Harvesting and Handling Innovations}

\subsubsection{Mowing, raking and field chopping experience}

This project offered the first opportunity to attempt field chopping of switchgrass on a private commercial farm. The initial attempt at this was made with a self-propelled forage chopper that was leased from a neighboring dairy where it was used to make silage. This chopping operation involved removal of annual ryegrass weed material in May of 1998. Ryegrass did not chop as finely as did switchgrass, and as mentioned earlier, caught fire from spontaneous combustion after stacking for several months.

Unfortunately, the neighboring dairy closed and the large chopper was sold before the formal start of this project. Consequently, a smaller pull-behind chopper and a highdump silage wagon were leased. In fall of 1998 and 1999, switchgrass was mown with a mower conditioner (see Figure 5). Typically, the yield of switchgrass is high enough that there is adequate material in the mown swath to eliminate the need for raking. This means that once dry, the switchgrass can be picked up directly from the swath by a round baler or a forage chopper. However, in all three years (1998, 1999 and 2000), yield was not high enough to do this, so 3 swaths were generally raked into a single windrow prior to baling or chopping. In addition, both baling and or chopping were used to collect the switchgrass in order to complete harvesting as quickly as possible in the narrow window of time between corn and cotton harvests (accommodating the Wilson Farms' schedule).

In fall of 1998, the 120 acres of switchgrass at Winterboro were field chopped and stored in three stacks, while the 80 acres at Lincoln were baled to save time. None of the stacks of switchgrass caught fire, even though they were not protected from the weather, and except for the surface 6 inches, stacks remained dry for about 6 months. In 1999, some of the 80 -acre field at Lincoln was chopped and stored in a stack, and some was baled.

During the course of these activities, two problems arose. First, switchgrass stubble caused frequent flats in the front tires of tractors and in the tires of implements, and occasionally, even in the back tires of tractors. It was assumed that this would be more of a problem with Alamo switchgrass than with varieties that have thinner stems, such as Cave-in-Rock. However, recent discussions with farmers involved in the Chariton Valley project indicated that this has also been a problem with Cave-in-Rock, although not as frequent. 


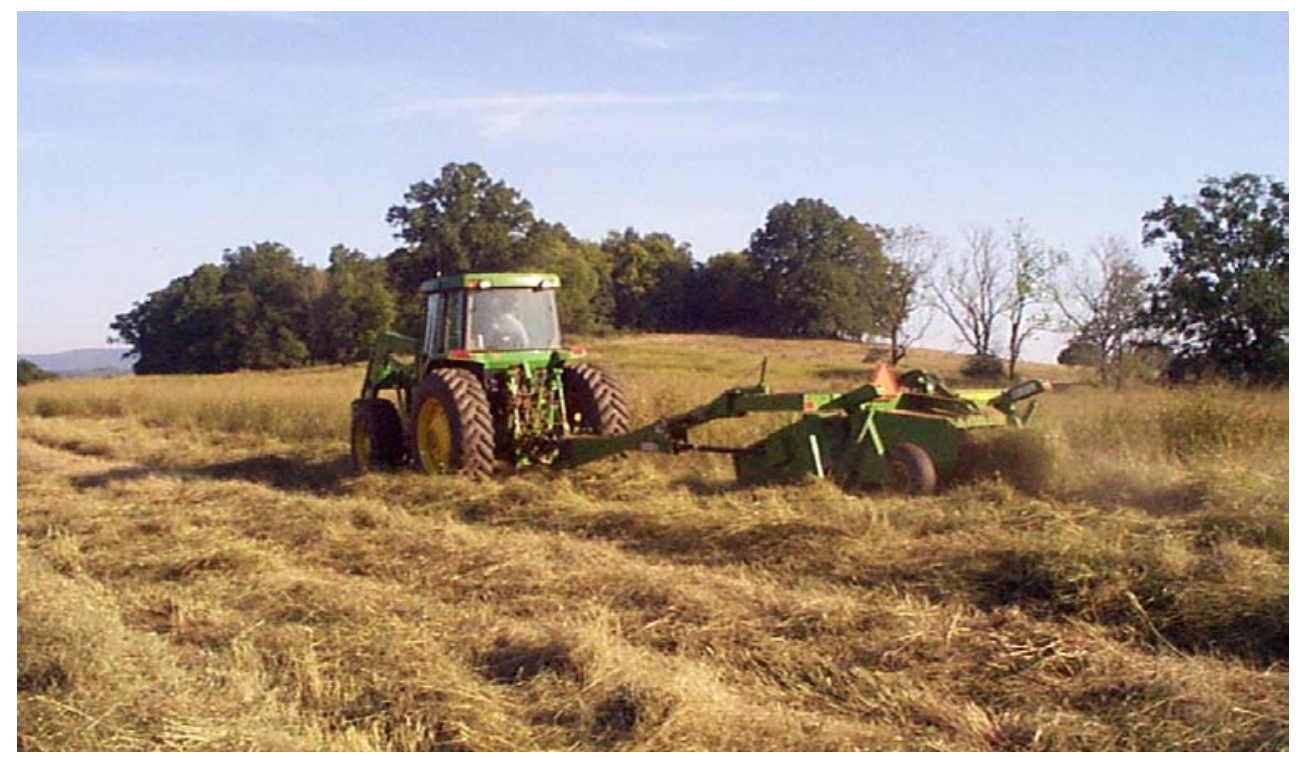

Figure 5. Mowing during the 1998 harvest at Winterboro.

The other problem which arose was damage to the blades in the forage chopper, and the need to sharpen these blades much more frequently than is usual during silage operations. Initially it was assumed that this was related to the fact that switchgrass was dry, whereas silage is relatively wet. However, it was evident that the blades of the chopper were actually being chipped, rather than being just evenly worn, as one would expect if it were just the low moisture content of the grass that was causing the problem. Subsequent observation made it clear that the cause of this chipping of the blades in the chopper was small pebbles that were becoming lodged in the windrow during raking, as a result of the rake being set too low. Consequently, the rake was raised, virtually eliminating the problem. However, higher yields would eliminate the need for raking.

\subsubsection{Module-builder test}

This test was not part of our original proposal. However, an attempt was made to create a switchgrass module with a cotton-module builder. The aim was to investigate the technical feasibility of this process in order to assess whether handling and transport costs, and storage losses, could be reduced by using cotton equipment and trucks that are normally used for only 2 months of the year. Figure 6 shows the module builder preparing the switchgrass module.

Chopped switchgrass was dumped directly out of the high-dump silage wagon into a cotton-module builder. We estimate that the module contained about 14 dry tons (5 silage-wagon loads of about 2.8 tons each). Figure 7 shows the switchgrass module. 


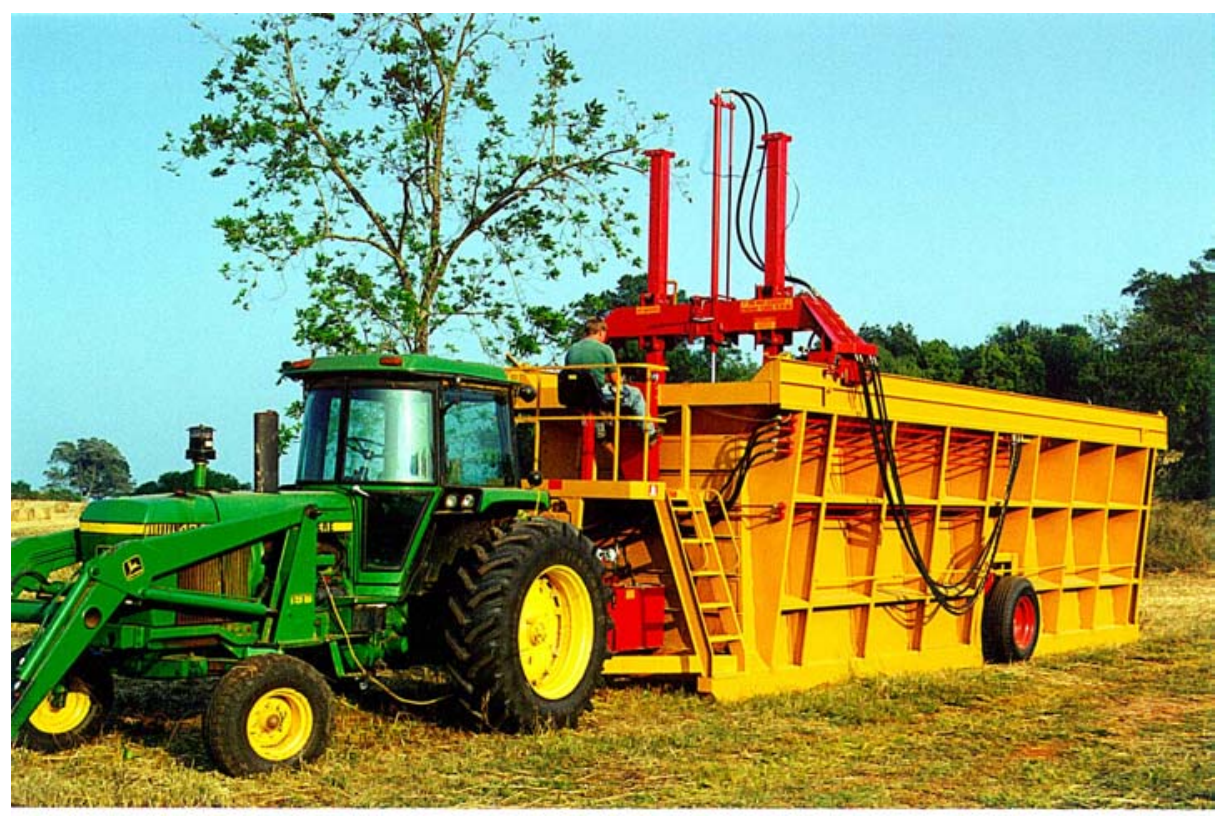

Figure 6. Module builder.

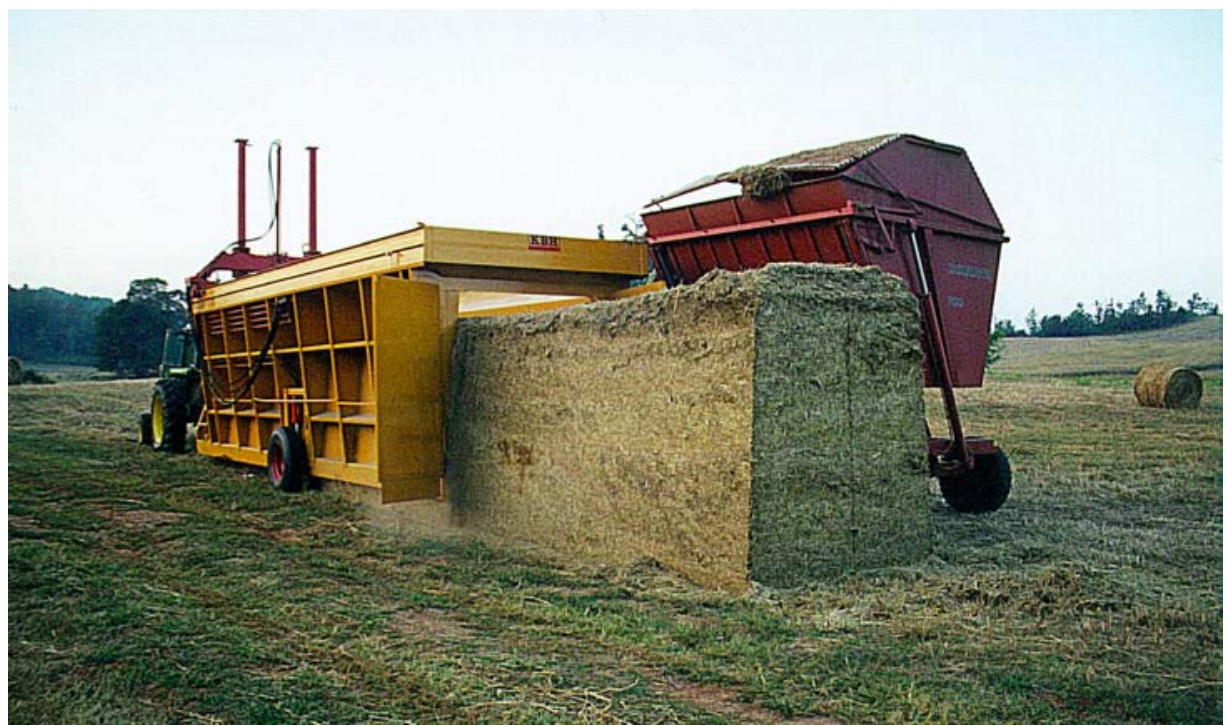

Figure 7. Module of switchgrass.

The module remained intact when the module builder was removed, but tended to disintegrate when an attempt was made to load it onto a cotton-module truck. This was probably due to the small size of switchgrass particles: most were a half-inch or less in length. However, if chopping was adjusted to produce longer particles, this process could well be successful. Furthermore, based on observation, the switchgrass appeared to be better preserved in the module than in loose stacks, probably because of the greater compaction. 


\subsection{Economic Model}

\subsubsection{Introduction}

Economic analysis of a potential industry required to supply switchgrass as a bio-fuel was approached through enterprise budget modeling. For many years, agricultural economists and agricultural engineers have cooperated to produce farm level crop budgets delineating cultural practices, production costs and expected returns for the major crops produced in each agricultural region. Although not formally standardized, these budgets have evolved to follow common patterns, and they routinely rely upon some common data and methodologies, such as the parameters and procedures for estimating machinery costs. In keeping with the general form and data sources for crop budgets, researchers developed an interactive spreadsheet model that provides flexibility in estimating costs for a selected variety of approaches to producing, processing, and transporting switchgrass for use as a bio-fuel. Crop budgets are traditionally limited to on farm production, implicitly leaving post-harvest processing and transportation to other entities. This model extends its projections to processing the crop into a useable form and transporting it to the end user.

\subsubsection{Data and Methods}

Economic analyses of established industries have the advantage of beginning with information about existing structure and practices. However, speculating on the basis of limited test plot experience about which configurations of personnel, equipment and methods may ultimately provide efficient commercial scale production for a hypothetical industry is inherently susceptible to error. There are innumerable variations in market structure and production methods currently in use throughout agricultural industries, and, for the most part, agricultural industries and markets continuously evolve and adapt to new developments. It is, therefore, vitally important to delineate fully the assumptions that were made in order to accomplish this economic analysis of the potential of switchgrass as a bio-fuel to be used co-firing electrical generation plants.

Many of the methods for production, processing and handling that are projected in this analysis are direct extensions of the methods used in conducting switchgrass research to date, while others are borrowed from similar forage crops. At the industry perspective, this analysis assumes a single level market structure composed of direct contracting relationships between generating facilities and farmers for the production, processing and delivery of the switchgrass bio-fuel to the generating facility in a form approximately ready for use. (The optimal form for use in combination with coal is still being determined.) At the farm level, the analysis identifies and delineates 4 alternatives 
for processing and transporting the crop. As invariably happens, possibly better alternatives were suggested through insights gained after working with the resultant model. This report will first describe the assumptions that were used in the model and the results obtained. Subsequently, a few possible extensions or modifications will be mentioned that could possibly result in a closer approximation to the shape of the industry that is likely to evolve following exposure to a confluence of technical, market and regulatory forces.

As previously stated, fundamental information for estimating crop budgets is normally provided by local Cooperative Extension Service personnel and university research faculty with first hand knowledge about prevailing production practices and crop yields on well managed farms. In this instance, substitute information had to be derived from Experiment Station test plot data, the limited experiences of one farmer producing switchgrass in Northern Alabama, and the informed conjectures of university researchers with experience in other forage crops. Consequently, it was deemed appropriate to design the model so that key variables could be easily changed, to accommodate new information and/or test the sensitivity of results to alternative specifications.

Individual farms differ in many important ways, including the quality and quantity of resources available as well as the skills and preferences of the managers. Thus, there is a long-standing assumption underlying the practice of estimating crop budgets. Recognizing that farm level results are stochastic, while budgets are deterministic, budget projections aim to reflect average results. It is assumed that better than average returns will appropriately compensate superior endowments, management or luck, while below average returns will similarly adjust the compensation for less desirable or fortunate situations.

\subsubsection{Model}

The spreadsheet model consists of ten worksheets as outlined below:

- Summary Page: contains variables and assumptions used throughout the model, and summarizes the results obtained from selected combinations of the other worksheets.

- Establishment 1: projects the costs of establishing the crop on sod.

- Establishment 2: projects the costs of establishing the crop on previously cropped land.

- Maintenance: projects annual stand maintenance practices and costs.

- Harvest 1: projects the costs for annual harvesting into large round bales. 
- Harvest 2: projects the costs for annual harvesting with a field chopper.

- Transportation 1: projects costs for transporting baled biomass and grinding the material at the point of use.

- Transportation 2: projects costs of transporting loose chop in a walking floor trailer.

- Transportation 3: projects compacting loose chop with a cotton module builder, transporting the material with a module hauler, and feeding the modules into the generating facility with a module feeder.

- Transportation 4: projects costs for compressing loose chop into pellets and transporting bulk pellets by walking floor trailer.

- Machinery Calculator: provides per hour machinery cost estimates for the equipment designated on other worksheets. Also contains selected machinery, not designated in the original formulations, that a user might wish to employ in an alternate evaluation.

As explained above, the Summary Page contains most of the variables that are used in multiple places throughout the model. Thus, alternative specifications of these variables need be entered in only one place. These variables include the unit size ( 1 acre is traditional enterprise unit in budgeting), personal property tax rate, insurance rate, a general overhead charge rate, farm labor wage rate, annual crop yield, stand life of the crop, annual cropland rental value, mileage from farm to power plant, farm fuel or energy prices (no hwy. taxes), and the hauling capacities of highway trucks under each transportation option. Other variables that are not specified in common throughout the model, such as machinery compliments, pesticides and fertilizers, are delineated on individual worksheets, and are also designed to be easily modified by a user.

Switchgrass stubble, following mowing, is stiff, sharp, and very damaging to normal water or air filled equipment tires. These budgets assume that suitable equipment or tire inflation materials are available at little or no extra cost.

Three of the transportation scenarios terminate projections at the point the biomass is delivered to the generating facility in a form ready to be used. There is no provision for feeding it into the boilers. However, due to the compacted form of material processed using a cotton module builder, it is necessary to decompose the modules at the generating plant. Transportation scenario 3 , includes the expense of a cotton module feeder, a piece of equipment designed to feed cotton modules into ginning machinery. The scenario assumes that this equipment can be easily adapted to operate with the boiler fueling systems. In case this option is not desired, the equipment can be simply zeroed out in the transportation option 3-machinery complement. 
More details of the model are included in the report in Appendix B.

\subsubsection{Typical Results}

Figure 8 depicts estimates generated as yield levels increase for each of the 4 transportation methods; round baled, chopped, modularized, and pelleted. The round bales are hauled as such, to be ground with a tub grinder at the point of use. The other three options are first harvested with a forage chopper. The material is then either hauled as loose chop in a walking floor trailer, compacted using a cotton module builder and transported with module hauler, or pelleted and hauled in a walking floor trailer. The hauling distance was set at 50 miles for this example and the crop was assumed to have been established on cultivated land, obtaining a 10-year stand life. These estimates indicate that increased yields can generate savings with each transportation method, however, potential savings level of after about 8 tons per acre. The reasons behind this are not known with certainty, but a possible explanation could be that harvesting and processing equipment designed for use on lower yielding forage crops is inadequate to fully exploit the potential savings with higher yields. Perhaps specialized equipment would ultimately reshape these relationships. Figure 9 was included to supplement the information in Figure 8. It illustrates the linear relationships between the distance from the farm to the generating plant and total costs. Handling and loading efficiency appear to be more operative than distance in determining cost differences.

A key point, on which little data could be found, is the hauling capacities of trucks for each of the processing options. The best available estimates assume that trucks can haul 20 tons of round bales, 15 tons of loose chop, modules weighing at least 14 tons, and 30 tons of pellets. Figure 10 shows estimated total costs for various truck hauling capacities. This graph is an example of using the model for sensitivity analysis. It is, of course, highly unrealistic to expect that enough of the relatively light loose chop can be loaded into a truck to reach the higher load projections included in this comparison. These results depict the trade off between hauling costs and additional processing to increase the density of the material.

Figure 11 projects the effect of stand life on total costs for modularized switchgrass at three different annual yield levels. Shorter stand lives, of course, adversely affect costs, but the effects taper off after about 6 years and are further mitigated as higher yields are obtained. 


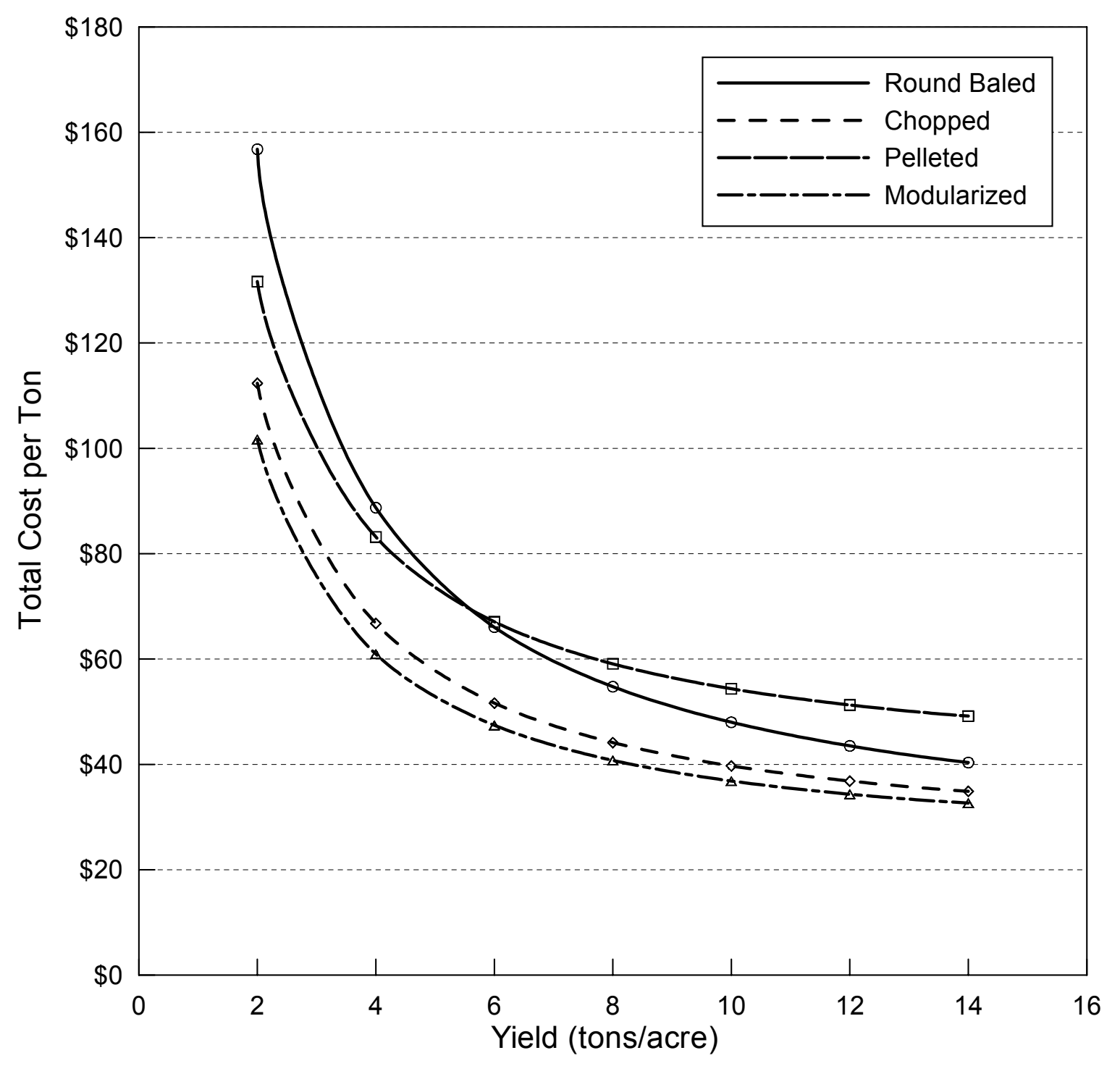

Figure 8. Cost per ton of switchgrass delivered depending on yield and transportation option (50-mile haul). 


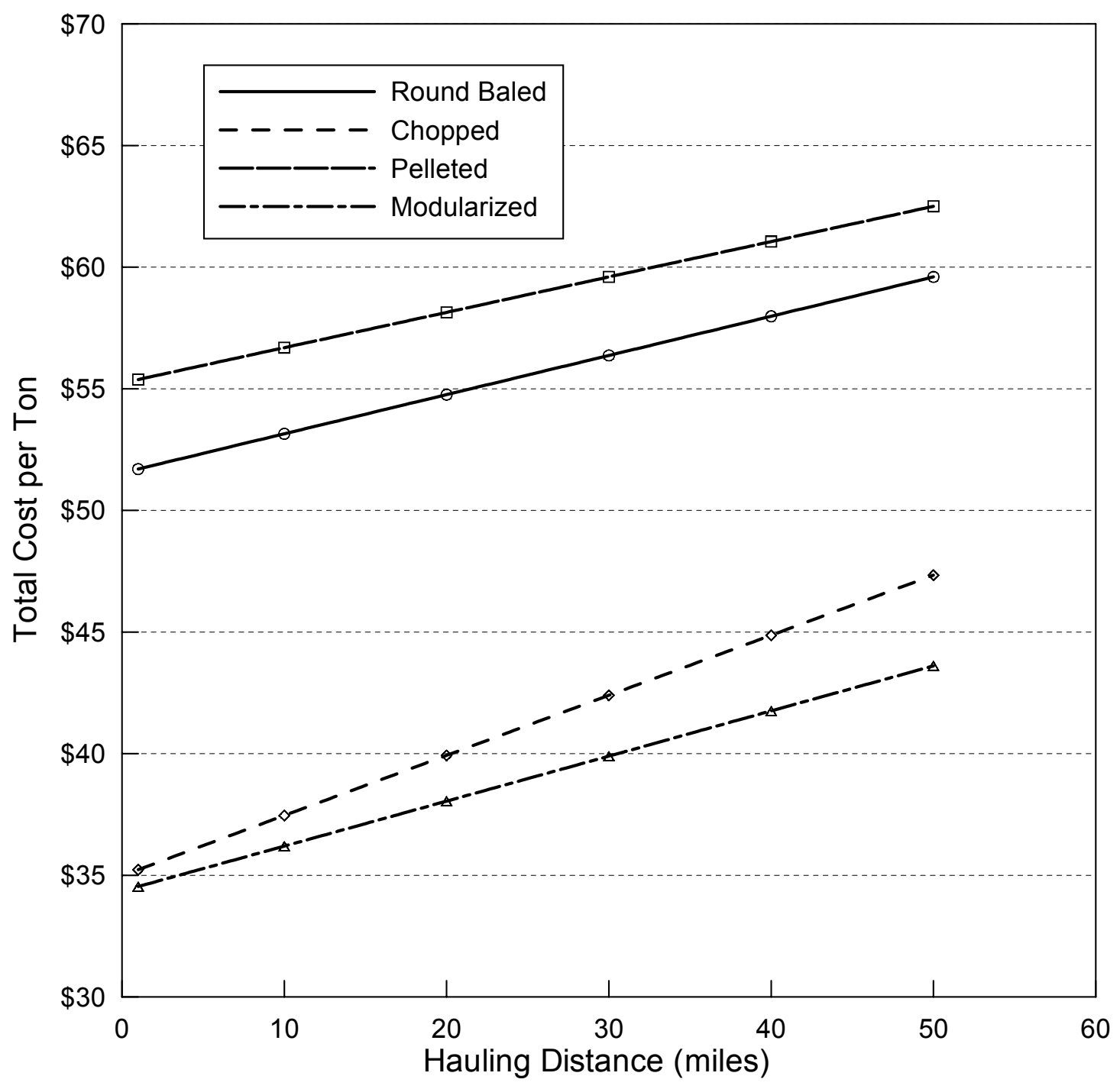

Figure 9. Cost per ton of switchgrass delivered depending on transportation option and hauling distance. 


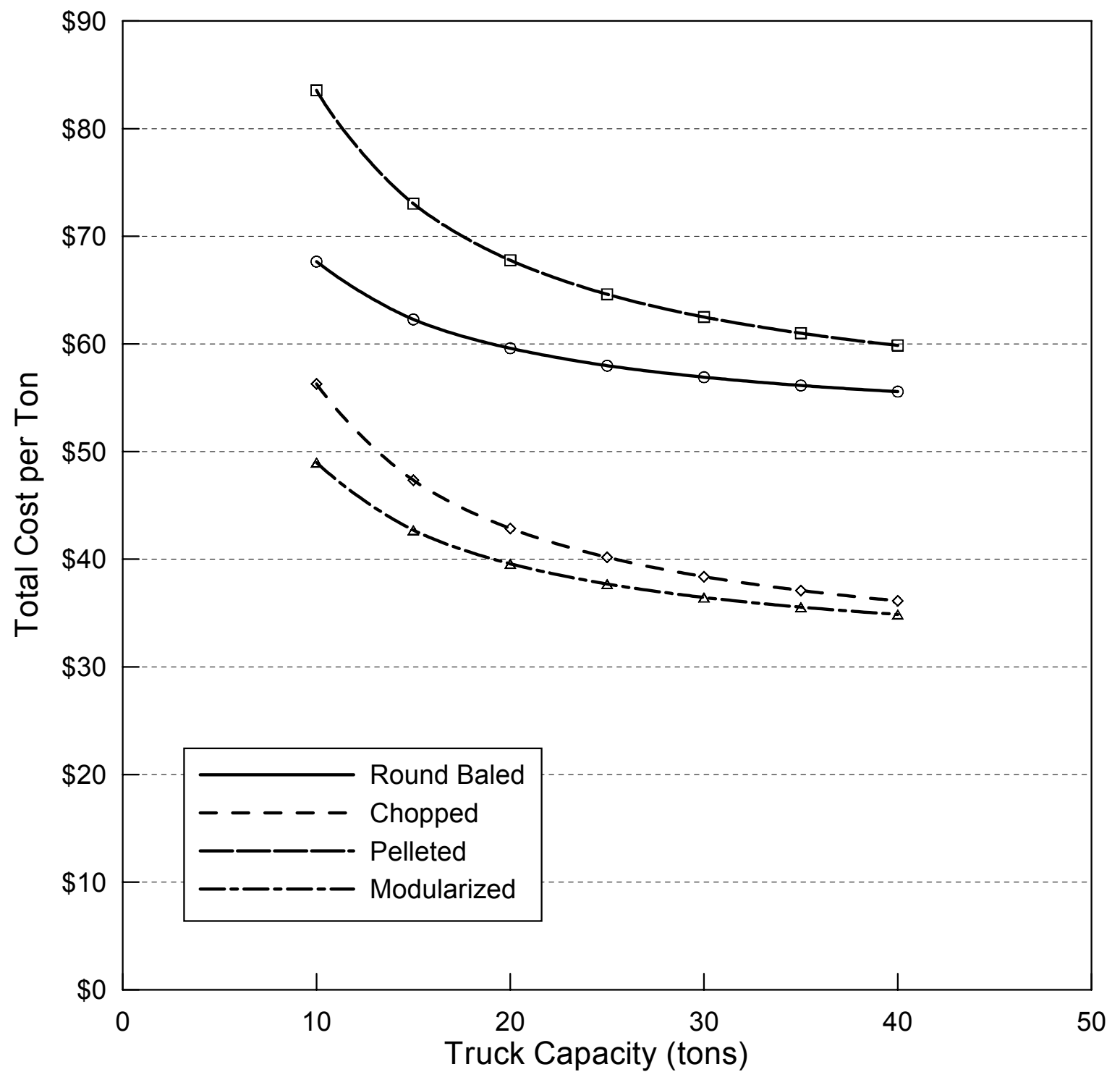

Figure 10. Effect of truck capacity on total cost (50-mile haul). 


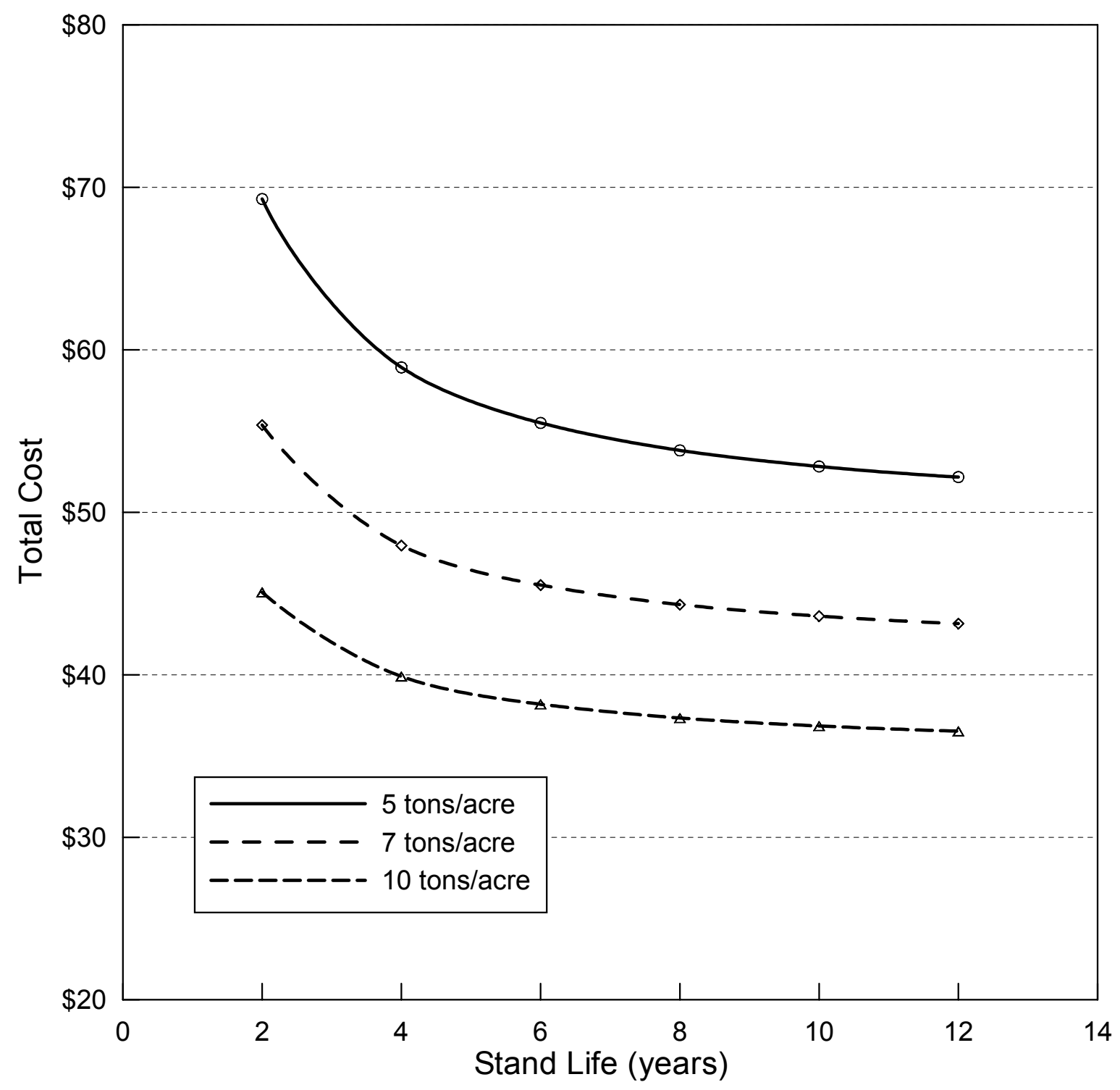

Figure 11. Effect of stand life on total cost of modularized switchgrass. 


\subsubsection{Supplementary Alternatives}

The cost associated with utilizing cotton module building equipment was based on the full cost of purchasing new equipment. However, it was discovered during discussions with personnel from cotton gins that substantial savings could possibly accrue through leasing idle cotton harvesting equipment. Cotton module builders are not currently utilized during the projected August harvest for switchgrass.

Similarly, it appears possible to reduce the equipment costs for pelleting, either by contracting with existing mills or purchasing used equipment, of which a great deal is available at the present time. However, another, similar alternative for densification of the switchgrass appears even better than pelleting equipment. Forage cubers are similar to pelleting equipment, but operate at less extreme internal pressures, consume less energy per ton processed and are reportedly less sensitive and much easier to operate. Variable costs for cubing as low as $\$ 10 /$ ton are currently claimed by a manufacturer. Furthermore, original experience in feeding loose chopped switchgrass into boilers has revealed problems with bridging. It has been suggested that pelleted or cubed forms would alleviate these problems.

\subsubsection{Summary}

The model has allowed researchers to derive a better understanding of the interaction among various cost factors for producing, processing and delivering switchgrass to power generation facilities. It has also helped to identify some potentially important areas for further research.

The model will continue to facilitate the process of moving switchgrass into commercial scale production, serving to inform both purchasers and producers on what to expect, and reducing the risks inherent in initial investments in commercial scale production.

The results obtained from this model indicate that at current prices, switchgrass bio-fuel will be about twice as expensive as coal per million BTUs. These estimates give credence to suggestions that programs such as carbon credits or credits for rural economic development could possibly achieve cost competitiveness for bio-fuels at a reasonable cost, well in proportion to the potential benefits to be derived. 


\subsection{Material Handling}

Material handling was a concern from the outset of the project. The relatively low bulk density of switchgrass compared to coal and the fibrous nature of the switchgrass were the bases of these concerns. We anticipated that these properties would affect transportation costs, homogeneity of the blending with coal, and pulverization (in terms of mill capacity, size reduction, and milling power requirements). Although these effects were observed and quantified, it was the flow properties of the blended material that had the most effect on the project outcome.

\subsubsection{Bulk Density}

The bulk density of chopped switchgrass from samples harvested for this project, without any compressive loading, was measured to be between 4.4 and $6.4 \mathrm{lb} / \mathrm{ft}^{3}$, with an average value of $5.7 \mathrm{lb} / \mathrm{ft}^{3}$. (Material harvested at Auburn University with their equipment had a measured bulk density of $7.8 \mathrm{lb} / \mathrm{ft}^{3}$.) This compares to the average value we measured for a Pratt Seam bituminous coal of $51.6 \mathrm{lb} / \mathrm{ft}^{3}$. Therefore, on a mass basis a blend of $10 \%$ switchgrass and $90 \%$ coal requires a combination of equal volumes of the two components. The same blend ratio (10:90 mass ratio of switchgrass:coal) using a Powder River Basin coal required eight parts coal to seven parts switchgrass.

Using the bulk density measurement as the guide to fuel mixing, and the volumetric approach to preparing the blends, contributed to some scatter in the heating value of the composite fuel. Variations in the switchgrass composition would not significantly affect the composite heating value. Figure 12 shows the range of blend ratios calculated from the fuel heating values for the nominal $5 \%$ and $10 \%$ fuel blends.

Inherent in our approach for co-milling and co-firing switchgrass with coal was the assumption that fuel loading, unloading, conveying, storing, and processing equipment was required to have volumetric capacity margins to accommodate the amount of material resulting from $10 \%$ switchgrass added to the coal feed system. This sitespecific qualification was a prerequisite to the co-milling approach, and our project was focused on the perceived bottle-neck in the system -- the pulverizer. Implications of the increased volume of material on the other fuel delivery systems were not studied in this project (primarily because of the change in co-firing approach). 


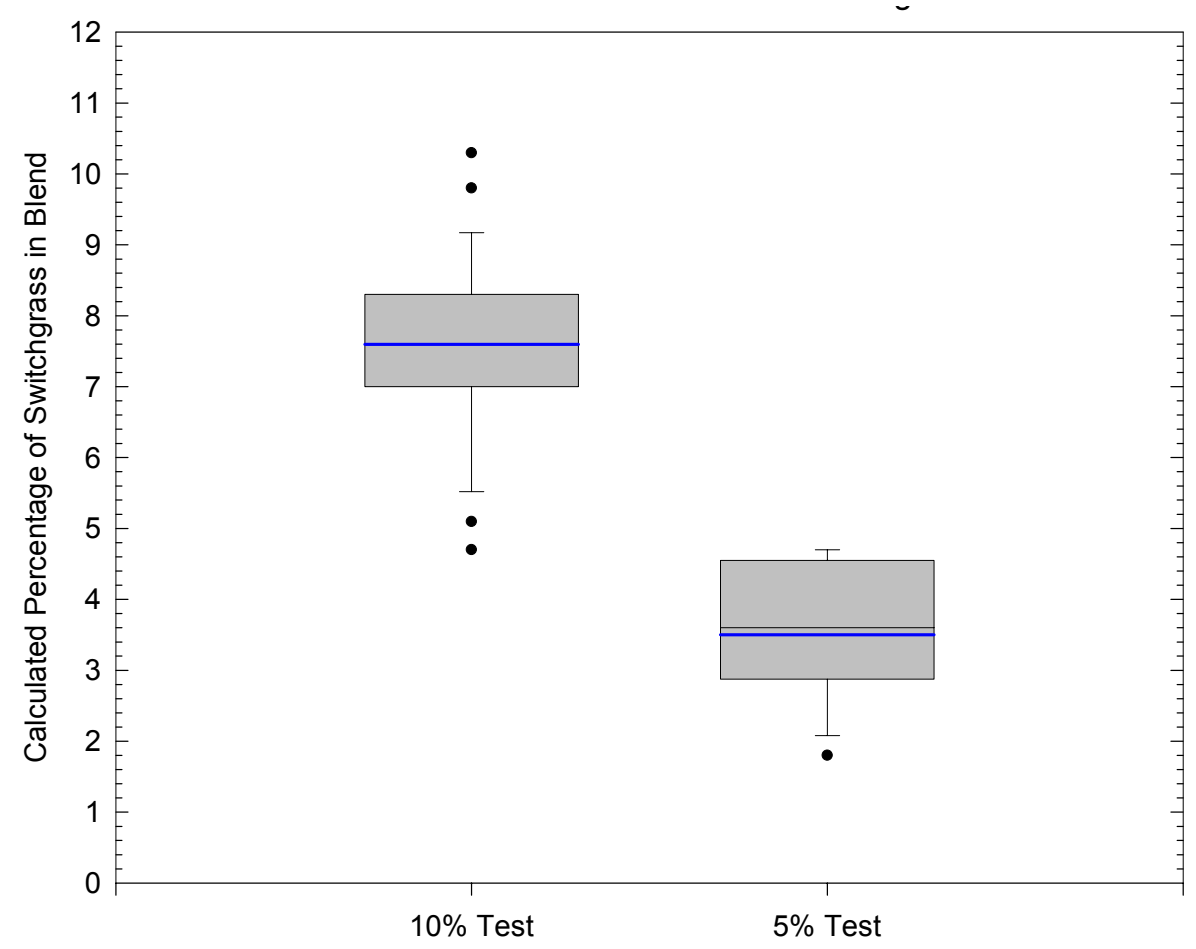

Figure 12. Calculated blend ratios based on heating values for the nominal blends.

\subsubsection{Size of Harvested Switchgrass}

Size of the switchgrass pieces was a fuel parameter that was known to have a bearing on blending, conveying, and milling the mixture of switchgrass and coal. Earlier experiments at Southern Research Institute had demonstrated that the throat of the classifier recycle chute in the Combustion Research Facility's CE Raymond bowl mill would clog if long, fibrous pieces of biomass (tree bark, in particular) were fed into the mill. It was also a concern that long pieces would require extra milling time to achieve the fuel size specification. In addition, the tendency of long fibers to form a plug that would not flow through the plant bunker and material conveying system was anticipated. These potential problems were an important consideration in the evaluation of the size of switchgrass produced by either the field chopping method of harvesting or the tub grinding of round bales.

Figure 13 shows the relative size of the switchgrass delivered for co-milling and co-firing tests. These size distributions were measured by sieving the switchgrass through a series of five sieves $(\# 4,8,14,20$, and 40$)$. We determined that mechanically agitating the sieves for at least 20 minutes produced a fairly repeatable and consistent size distribution. (There was still considerable scatter in the results from the tub ground 
material produced with 4-inch and 3-inch screens, but this is probably attributable to material variability and not a lack of reproducibility in the sieving procedure.) This figure shows that the field-chopping harvesting approach produced a slightly coarser product than did a tub grinder with 1 -inch and $1 / 2$-inch screens (the smallest we had available), though substantially finer than what the tub grinder produced with the larger screens.

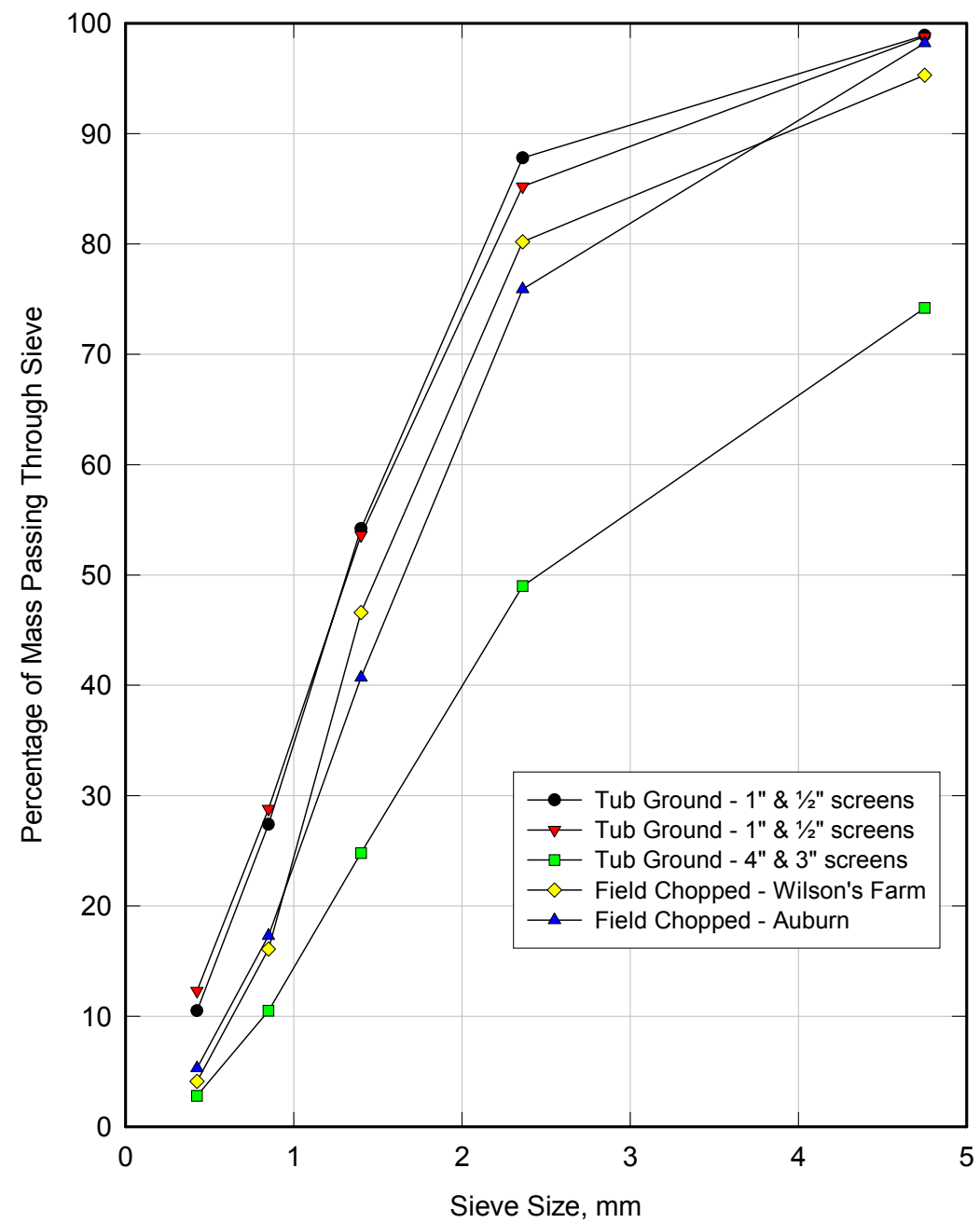

Figure 13. Size distributions of switchgrass measured with stacked sieves.

We received material at the Combustion Research Facility that was both field chopped and tub ground (with the fine screens). The switchgrass from either harvesting approach was used in subsequent milling and co-firing tests. A qualitative observation consistent with the measured size distributions was that the field chopped material from the Wilson's Farm had longer pieces in the coarsest size fraction than the tub ground material. There was less of this difference with the material harvested in Auburn. 
We were not able to feed $100 \%$ switchgrass through the hopper system supplying material to the pulverizer. However, we were able to feed a blend of fuels consisting of up to $15 \%$ switchgrass through our hopper and fuel milling system. To do this required care and attention to avoid plugging the hoppers and transport lines in our pilot plant. This difficulty caused us to devote special attention to the material flow properties, which are discussed in the following section.

\subsubsection{Flow Characteristics}

The premise of the co-firing approach set forth as the goal of this project was that existing plant equipment would be used to feed and pulverize the switchgrass material along with the coal. Initial plans for co-firing switchgrass with coal at Alabama Power's Plant Gadsden centered around mixing the chopped switchgrass with coal at the coal pile. According to those plans, the mixture would then be introduced through the reclaim into the coal handling system. The blend would have to pass through hoppers, conveying belts, crusher, coal storage bunkers, and pulverizer. This process has been used in several Southern Company plants for successfully co-firing low concentrations of different biomass materials, including sawdust, sander dust, tree trimming waste, and cardboard. However, the low bulk density of the switchgrass $\left(5-7 \mathrm{lb} / \mathrm{ft}^{3}\right)$ and the needle-like shape of the grass particles suggested that in a mix with coal the blend might not flow.

Observation of a mix of switchgrass with coal in the pilot-scale testing at the Combustion Research Facility (CRF) substantiated concerns regarding how the mix would flow in the bunkers at Gadsden. At Gadsden the coal exits each coal storage bunker through a converging exit. Difficulties in maintaining flow through the steeply sloped hoppers in the CRF served as an early warning of a potential problem at Gadsden. Therefore, before filling the bunkers of the power plant with a mix that might not pass through the system, Jenike and Johanson, Inc. (J\&J) of Westford, MA were contracted to conduct laboratory tests to characterize the flow properties of blends of the two materials. On samples furnished by Southern Company, J\&J performed compressibility, cohesive strength, and wall friction tests on coal alone and on 5\% switchgrass - 95\% coal mixtures (by mass). A plot of bulk density with compressive pressure in Figure 14 shows the distinct difference in properties of coal alone and a $5 \%$ blend with switchgrass. 


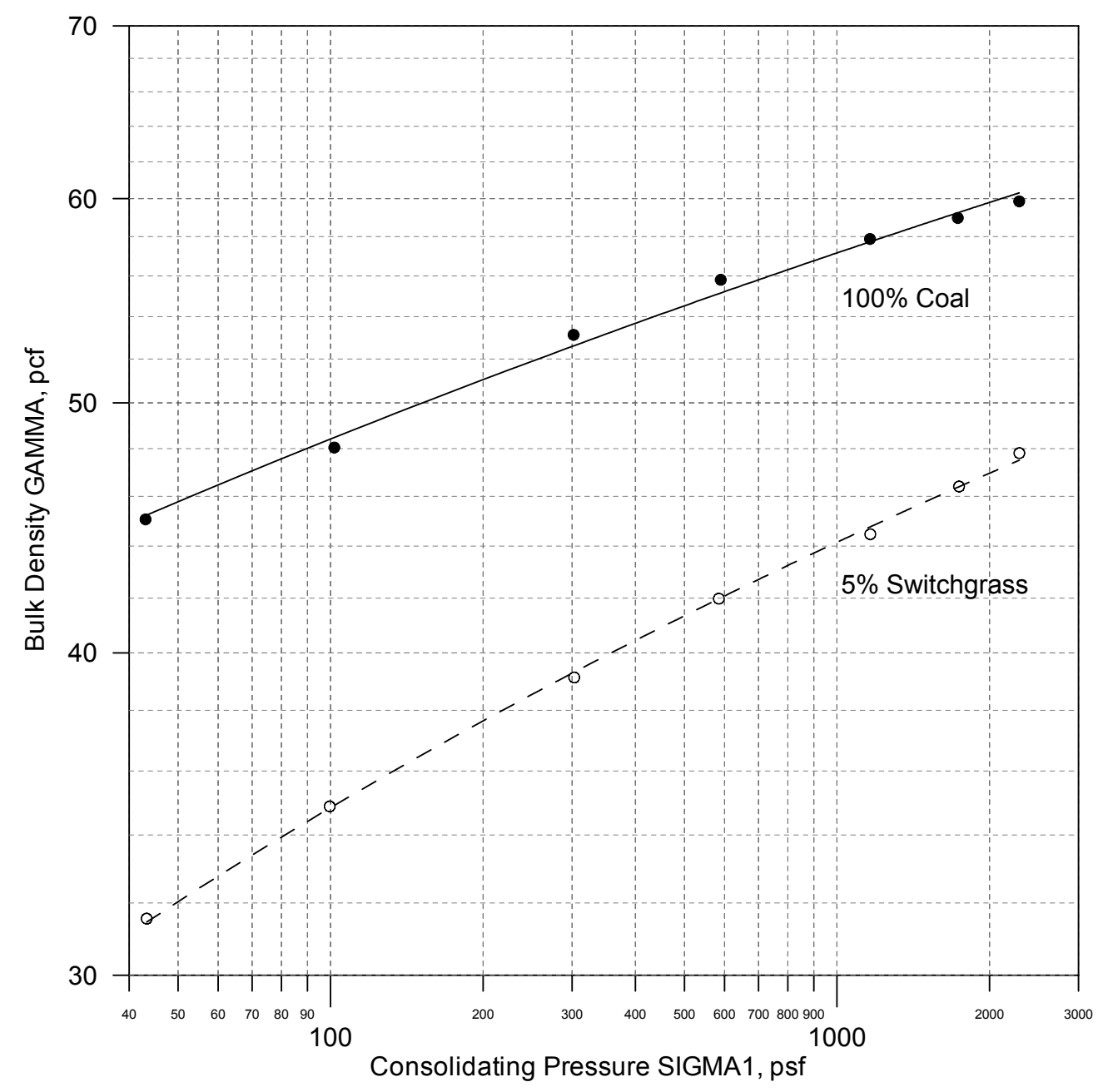

Figure 14. Bulk density versus load of coal and a blend with $5 \%$ switchgrass.

$\mathrm{J} \& \mathrm{~J}$ constructed a model bunker of the same material and with the same angle slopes ( $48^{\circ}$ from vertical) as the Plant Gadsden coal bunker. In tests, crushed coal would flow easily from this bunker when the bunker bottom was opened. This simulated well the actual field condition. However, a $5 \%$ mix of switchgrass with the coal would not flow. The low bulk density of the material together with the tendency of the grass particles to interact could not overcome the converging nature of the bunker bottom. Tests indicated that the walls of the bunker would need to be sloped as a maximum angle of $16^{\circ}$ from vertical for the material to flow continuously without bridging.

Based on this result together with the other laboratory tests, J\&J concluded that it would not be possible to reliably handle $5 \%$ switchgrass - 95\% coal blend in the existing bunker at Plant Gadsden. Higher percentages, such as the $10 \%$ switchgrass blend we were to test at Plant Gadsden, would have worse flow characteristics. 
Several options for mitigating these flow properties were considered. These included pre-processing the switchgrass to a finer and more consistent size before blending with the coal, pre-processing the switchgrass into pellets before blending with the coal, modifying the bunkers at Gadsden, and adding hardware for injecting and burning the switchgrass separately from the coal. The last option was selected by Southern Company and Alabama Power as an acceptable alternative to the original plan for comilling a blended fuel. Therefore, the material handling properties of switchgrass dramatically altered the project technical approach and work scope.

\subsection{Milling Results}

The combination of switchgrass and coal was successfully pulverized in the CERaymond bowl mill. The target fineness for pulverized fuel was $70 \%$ minus 200 mesh, or $70 \%$ finer than $75 \mu \mathrm{m}$. This fineness was readily achieved, as shown in Figure 15.

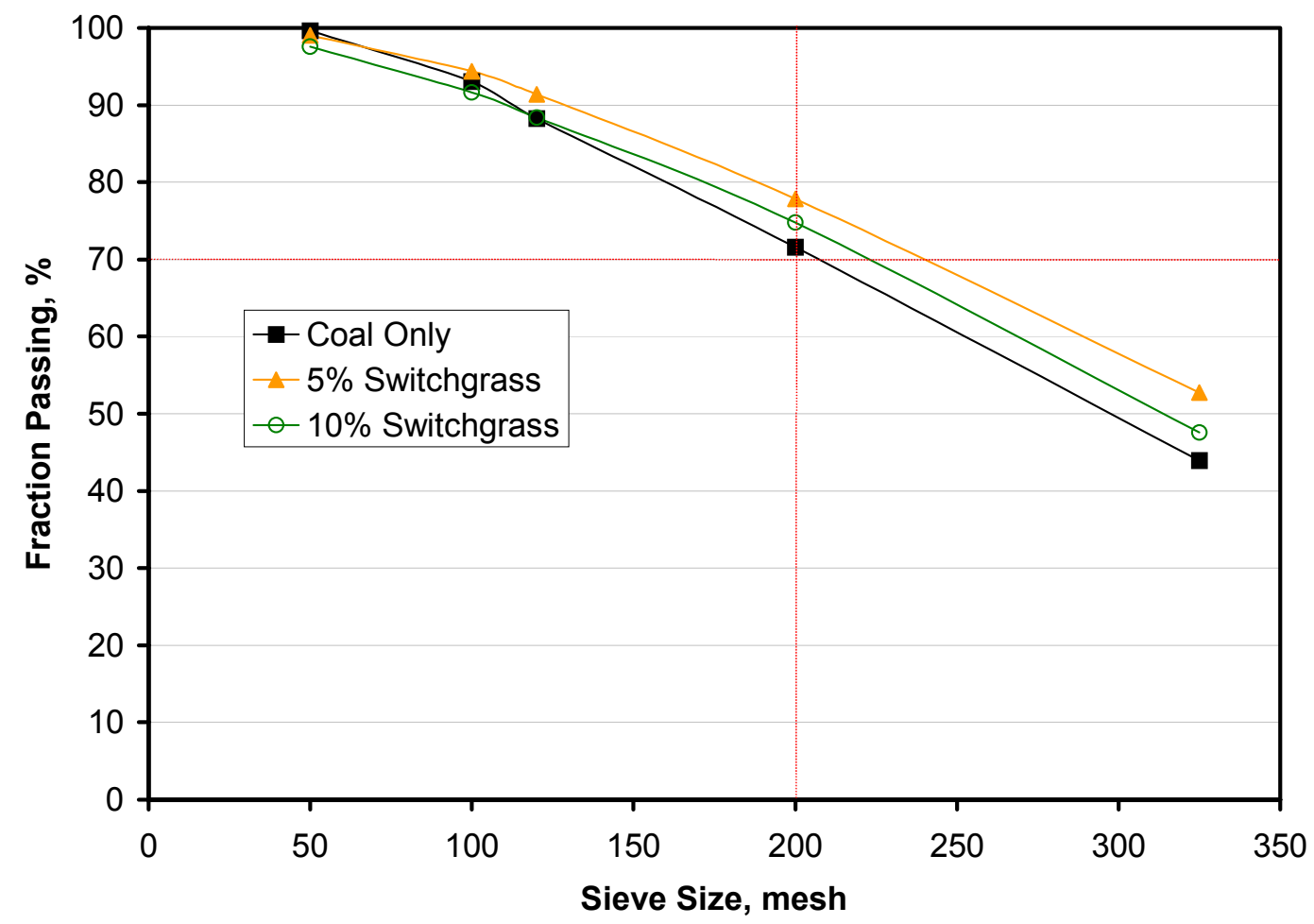

Figure 15. Size distributions of pulverized fuels.

Although the milling produced the composite size distribution that was specified for pulverized fuel, the product was inhomogeneous. Figure 16 shows the measured heating values of discrete sieve fractions of the pulverized fuel. For these fuel samples, the coal being pulverized had a higher heating value of $13,500 \mathrm{Btu} / \mathrm{lb}$ (as received) and 
the switchgrass had a higher heating value of approximately $7,300 \mathrm{Btu} / \mathrm{lb}$ (as received). (Since over $70 \%$ of the composite fuel was less than $75 \mu \mathrm{m}$, the average higher heating value was around 13,300 and 13,000 for the $5 \%$ and $10 \%$ blends, respectively.) The data plotted in Figure 16 illustrate that the pulverization of the blended materials produced distinctly different size distributions for the coal and the switchgrass fractions with switchgrass predominating in the coarsest fraction of material. This segregation is more pronounced with the higher switchgrass concentration.

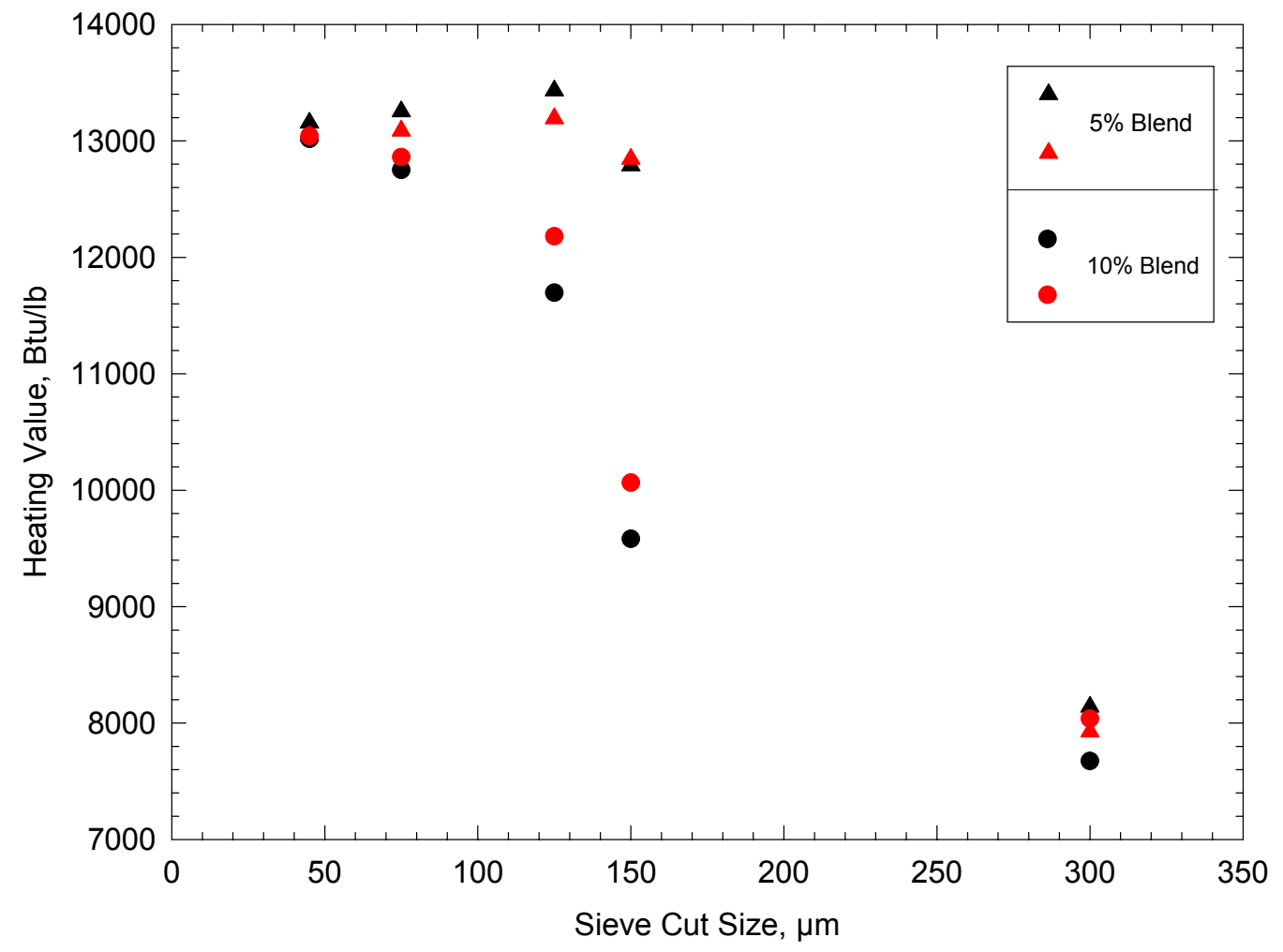

Figure 16. Heating value for each of sieve fraction of the pulverized fuel.

The CE-Raymond bowl mill has pulverized blends of both bituminous (Alabama Pratt Seam) and subbituminous (Powder River Basin Belle Ayre and Jacob's Ranch) coals. The combination of data from the bituminous coal and the PRB coals indicates that comilling equal volumes of coal and switchgrass (a 90:10 mass ratio) can be done in a Raymond bowl mill for a wide range of coals and achieve the criterion for fuel fineness. Milling of blends up to $80: 20$ coal-switchgrass mass ratio has also been accomplished.

An example of the milling comparison for the bituminous coal and the blend of coal and switchgrass is given in Table 4. These results were obtained without any attempt to optimize the milling operation for the blended fuel, focusing only on the fineness criterion for the pulverized fuel. 
Table 4. Comparison of milling performance for bituminous coal and a blended fuel.

\begin{tabular}{l|c|c|c|c}
$r \quad$ Coal: & $\%$ & 100 & 90 & $\%$ Diff. \\
\hline Switchgrass: & $\%$ & 0 & 10 & \\
\hline Heat Content & $\%$ & $70-73$ & $67-73$ & - \\
\hline Mill Output & $\mathrm{Btu} / \mathrm{lb}$ & 13520 & 12935 & -4 \\
\hline Mill Reject & $\mathrm{lb} / \mathrm{hr}$ & 1642 & 929 & -43 \\
\hline Mill Current & $\mathrm{lb} / \mathrm{hr}$ & 28.5 & 13.6 & -52 \\
\hline Specific Grinding Energy, gross & $\mathrm{Amps}$ & 44.4 & 45.1 & 1 \\
\hline Specific Grinding Energy, net & $\mathrm{kWh} / \mathrm{ton}$ & 16.3 & 29.2 & 79 \\
\hline Specific Drying Energy & $\mathrm{Btu} / \mathrm{lb}$ & 2.14 & 4.15 & 93 \\
\hline Mill Output & $\mathrm{MBtu} / \mathrm{hr}$ & 22.2 & 12.29 & -46 \\
\hline Specific Grinding Energy, gross & $\mathrm{kWh} / \mathrm{MBtu}$ & 0.602 & 1.129 & 88 \\
\hline Specific Grinding Energy, net & $\mathrm{kWh} / \mathrm{MBtu}$ & 0.079 & 0.160 & 102 \\
\hline Specific Drying Energy & $\mathrm{Btu} / \mathrm{MBtu}$ & 95.7 & 177.1 & 85 \\
\hline Hargrove Grindability Index & & 62 & $\mathrm{na}$ & \\
\hline
\end{tabular}

The data in Table 4 reveal significant throughput and energy consumption penalties for the blended fuel. The case with a Powder River Basin coal from the Jacob's Ranch mine is presented in Table 5. This case shows a much lower energy penalty and somewhat less of a throughput reduction.

Table 5. Comparison of milling performance for Powder River Basin coal and a blended fuel.

\begin{tabular}{|c|c|c|c|c|}
\hline $\begin{array}{r}\text { Coal: } \\
\text { Switchgrass: }\end{array}$ & $\begin{array}{l}\% \\
\%\end{array}$ & $\begin{array}{c}100 \\
0\end{array}$ & $\begin{array}{l}90 \\
10\end{array}$ & $\%$ Diff. \\
\hline Heat Content & Btu/lb & 10150 & 9400 & -7 \\
\hline Mill Output & $\mathrm{lb} / \mathrm{hr}$ & 1124 & 784 & -30 \\
\hline Mill Reject & $\mathrm{lb} / \mathrm{hr}$ & 10.2 & 3.5 & -66 \\
\hline Mill Current & Amps & 44.7 & 43.7 & -2 \\
\hline Specific Grinding Energy, gross & $\mathrm{kWh} / \mathrm{ton}$ & 24.5 & 33.8 & 38 \\
\hline Specific Grinding Energy, net & kWh/ton & 3.35 & 3.95 & 18 \\
\hline Specific Drying Energy & $\mathrm{Btu} / \mathrm{lb}$ & 171.4 & 187.7 & 10 \\
\hline Mill Output & MBtu/hr & 11.4 & 7.4 & -35 \\
\hline Specific Grinding Energy, gross & kWh/MBtu & 1.208 & 1.800 & 49 \\
\hline Specific Grinding Energy, net & $\mathrm{kWh} / \mathrm{MBtu}$ & 0.17 & 0.21 & 27 \\
\hline Specific Drying Energy & Btu/MBtu & 16882.3 & 19967.5 & 18 \\
\hline
\end{tabular}


Again, it must be said that the milling results in Tables 4 and 5 were obtained without attempting to perform a mill optimization. The mill was configured and operated to yield the requisite pulverized fuel fineness only. The mill optimization planned for this project was not completed when the material handling issues relative to the demonstration test site dictated direct injection as the co-firing approach. Nevertheless, it can be seen from these results that blending switchgrass and coal for co-milling will impose a constraint on mill throughput. The implications for mill energy are less readily extrapolated from the testing at the Southern Research Institute and Southern Company Combustion Research Facility because of the batch operating mode used to provide pulverized fuel to the pilot-scale furnace.

\subsection{Pilot-Scale Co-firing}

A major focus of the project plan was to perform co-firing tests in the Southern Research Institute / Southern Company Combustion Research Facility. This facility is designed for up to six million Btu per hour firing on natural gas or coal, which is equivalent to 1.75 MW thermal or about $0.6 \mathrm{MW}$ electric. The design of the facility was carefully chosen to provide a close simulation of the physical processes that occur in a full-scale utility boiler. It is described in Appendix $\mathrm{C}$.

The matrix of co-firing tests that was planned in this project included nine weeks of combustion experiments. The primary variables in the matrix were coal type (eastern bituminous or Powder River Basin), burner configuration (wall-fired simulation or tangential-fired simulation), and blend ratio of switchgrass to coal (up to 20\%). The emphasis in the test matrix, as in the program overall, was the documentation of technical advantages and identification of potential problems relative to combustion or emissions that would be encountered in the full-scale demonstration at Plant Gadsden. For that reason, the cases with the Pratt Seam bituminous coal and the tangential-firing configuration were of most direct interest. The other co-firing variables were opportunities to define economic issues in fuel selection and to generalize the testing to extend the potential application to much of the coal-fired boiler population.

Typical compositions of the fuels are given in Table 6. 
Table 6. Co-firing Test Fuels

\begin{tabular}{|c|c|c|c|c|c|}
\hline \multicolumn{2}{|c|}{ AS RECEIVED - Proximate } & $\begin{array}{c}\text { Pratt Seam } \\
\text { Bituminous } \\
\text { Coal }\end{array}$ & $\begin{array}{c}\text { Jacobs } \\
\text { Ranch PRB } \\
\text { Coal }\end{array}$ & $\mid \begin{array}{l}\text { Mechanically } \\
\text { Harvested } \\
\text { Switchgrass }\end{array}$ & $\begin{array}{c}\text { Manually } \\
\text { Harvested } \\
\text { Switchgrass }\end{array}$ \\
\hline Moisture, Total & $\%$ by wt & 1.15 & 29.92 & 9.53 & 8.89 \\
\hline Ash & $\%$ by wt & 11.28 & 4.87 & 5.95 & 3.93 \\
\hline$\overline{\text { Volatile }}$ & $\%$ by wt & 24.93 & 34.24 & 69.03 & 81.79 \\
\hline Fixed Carbon & $\%$ by wt & 62.64 & 30.97 & 15.49 & 5.39 \\
\hline Heat of Combustion & Btu/lb & 13513 & 8400 & 7333 & 7421 \\
\hline Sulfur & $\%$ by wt & 1.57 & 0.34 & 0.20 & 0.10 \\
\hline \multicolumn{2}{|c|}{ AS RECEIVED - Ultimate } & & & & \\
\hline Carbon & $\%$ by wt & 81.00 & 53.17 & 40.54 & 43.55 \\
\hline Hydrogen & $\%$ by wt & 3.99 & 1.98 & 5.28 & 5.13 \\
\hline Nitrogen & $\%$ by wt & 1.63 & 0.76 & 0.92 & 0.79 \\
\hline Oxygen (difference) & $\%$ by wt & -0.62 & 8.96 & 37.57 & 37.61 \\
\hline \multicolumn{2}{|c|}{ DRY BASIS - Proximate } & & & & \\
\hline$\overline{\text { Ash }}$ & $\%$ by wt & 11.41 & 6.95 & 6.58 & 4.31 \\
\hline Volatile & $\%$ by wt & 25.22 & 48.86 & 76.30 & 89.77 \\
\hline Fixed Carbon & $\%$ by wt & 63.37 & 44.19 & 17.12 & 5.92 \\
\hline Heat of Combustion & Btu/lb & 13670 & 11986 & 8105 & 8145 \\
\hline Sulfur & $\%$ by wt & 1.59 & 0.49 & 0.22 & 0.11 \\
\hline \multicolumn{2}{|c|}{ ASH MINERALS - Ignited as oxide } & & & & \\
\hline Aluminum oxide & $\%$ by wt & 29.78 & 15.4 & 8.39 & 1.08 \\
\hline Calcium oxide & $\%$ by $w t$ & 1.12 & 27.0 & 4.62 & 12.77 \\
\hline Iron oxide & $\%$ by wt & 13.64 & 8.0 & 5.82 & 0.34 \\
\hline Magnesium oxide & $\%$ by wt & 0.85 & 4.7 & 3.65 & 20.41 \\
\hline Phosphorus pentoxide & $\%$ by wt & 0.55 & 0.36 & 2.73 & 5.89 \\
\hline Potassium oxide & $\%$ by wt & 2.28 & 0.29 & 1.95 & 2.92 \\
\hline Silicon dioxide & $\%$ by wt & 46.51 & 27.2 & 62.71 & 48.56 \\
\hline Sodium oxide & $\%$ by wt & 0.30 & 2.1 & 0.59 & 2.38 \\
\hline Sulfur trioxide & $\%$ by wt & 0.05 & 15.1 & 2.28 & 3.83 \\
\hline Titanium oxide & $\%$ by wt & 1.67 & 2.2 & 0.53 & 0.07 \\
\hline
\end{tabular}

Dr. Bransby took the manually harvested switchgrass from research plots at Auburn University. This sample is presented as a reference for the composition of the switchgrass apart from any contamination by soil entrained with the biomass during harvesting. The case more representative of the fuel used in our combustion tests is the mechanically harvested switchgrass. This material was harvested using field chopping.

There is more variability in the composition of switchgrass and coal than is implied by placing such a limited set of data in Table 6. In particular, the chemical composition of 
the switchgrass samples is dependent on harvest conditions and the inclusion of soil with the samples, as well as the factors discussed above in Section 4.1.2. However, the variability in switchgrass mineral composition is so greatly damped by the dilution of the ash with the coal ash when firing $90 \%$ coal that within the scatter of the compositions we measured the variability was not consequential.

Five major co-firing tests were completed instead of the nine originally planned. The tests included baseline coal tests, co-milled fuel tests with the bituminous and the PRB coal, and a direct injection test case that was added after the plans for the demonstration testing at Gadsden were finalized. These tests are summarized below.

\subsubsection{Co-milled Fuels}

The first tests that were conducted were with a Pratt Seam bituminous coal and $5 \%$ and $10 \%$ switchgrass blends (mass basis). In the initial test switchgrass was added to the coal just as the coal entered the pulverizer, and then into the coal crusher system upstream of the pulverizer. As this was a pneumatic system it tended to segregate the coal and switchgrass. A subsequent modification to the CRF coal milling circuit eliminated pneumatic fuel conveying to the pulverizer and allowed better control of the fuel blend consistency. Nevertheless, there was some variability in the concentrations of switchgrass in the pulverized coal being burned as shown in Figure 17 (a repeat of Figure 12). The average concentrations of switchgrass in these two cases were 7.6 and $3.5 \%$ (heating value basis).

The most important observations from these tests were as follows:

- There was no effect observable on flame stability or attachment at the burner.

- Burning embers of switchgrass were seen as high as the entrance to the convective section of the combustor, although there was actually a measured decrease in carbon carryover at the exit of the convective section during co-firing.

- Slagging was indicated in the furnace bottom at a $2.5 \%$ furnace exit $\mathrm{O}_{2}$ firing condition, but no worse than was observed with the Pratt Seam coal alone. Slagging was not a problem at $3.5 \%$ and $4.5 \%$ furnace exit $\mathrm{O}_{2}$ firing conditions.

- There was no evidence of fouling at any furnace test condition.

- $\mathrm{SO}_{2}$ concentration in the flue gas decreased proportionally with the rate of switchgrass injection.

- NOx concentration in the flue gas was decreased as a result of co-firing.

- There was no change in the particle size distribution of the ash or the resistivity of the ash that would alter the performance of particulate control systems. 


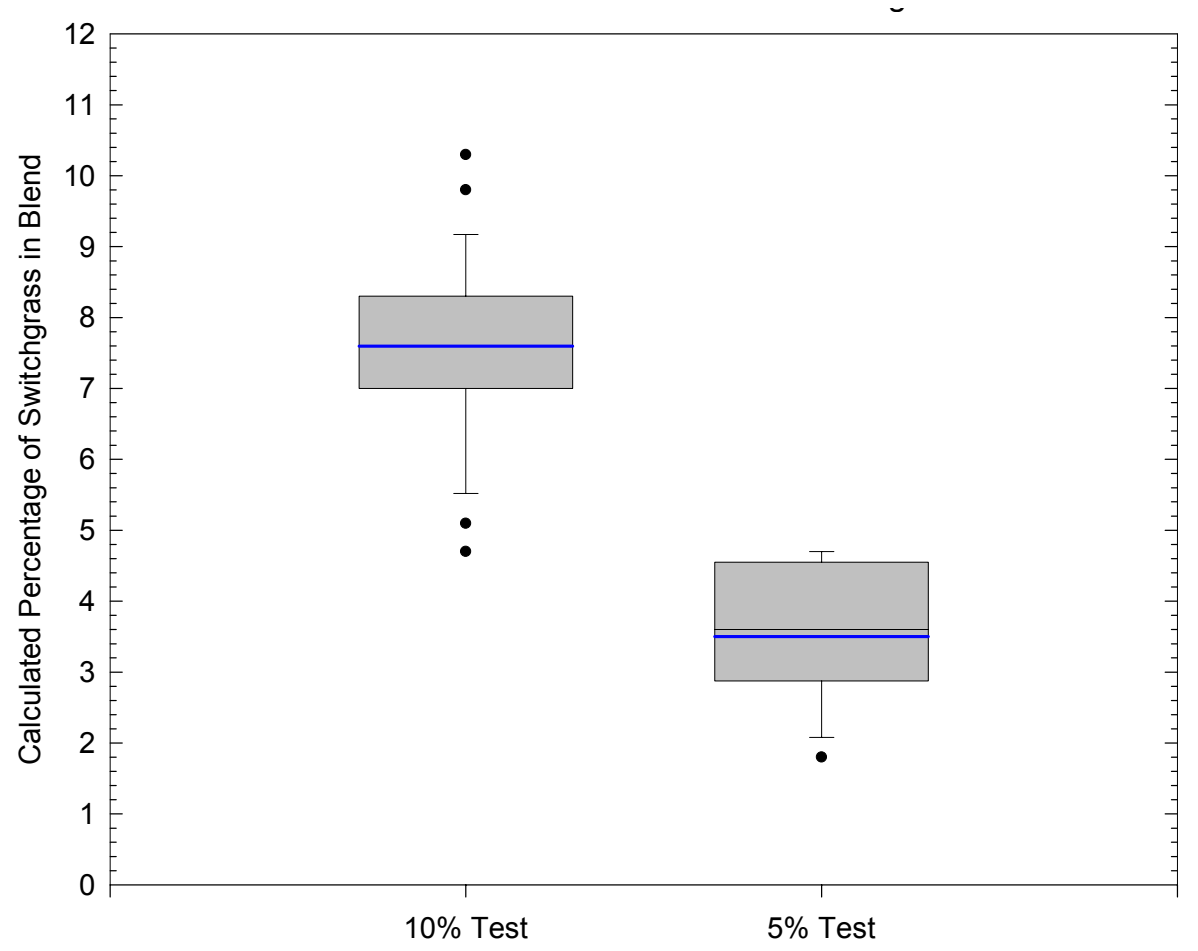

Figure 17. Calculated blend ratios based on heating values for the nominal blends.

\subsubsection{Ash properties}

There were concerns with the potential for the switchgrass to exacerbate slagging and fouling in the furnace and convective sections of the combustor. These related to some relatively high alkali concentrations reported in the literature for switchgrass (14). The analyses that have been conducted during this project have sometimes yielded substantially higher alkali contents than are presented in Table 6. For example, the average composition of one delivery of switchgrass to the Combustion Research Facility is shown in Table 7.

Both of the slagging potential guidelines show marginal prospects for formation of slag with this sample in spite of the high level of potassium, a key indicator. The mechanism for the formation of eutectics makes extrapolation of slagging potentials from combinations of ashes difficult. Nevertheless, a 90:10 ratio of coal and switchgrass derived ashes did not exhibit any slagging or fouling deposition that exceeded the observed behavior of the coal alone. 
Table 7. Switchgrass ash composition measured after ashing samples at two ignition temperatures.

\begin{tabular}{|c|c|c|}
\hline Ignition Temp. ${ }^{\circ} \mathrm{C}$ & 600 & 750 \\
\hline \multicolumn{3}{|c|}{ Mineral Composition, \% as oxide } \\
\hline $\mathrm{Na}_{2} \mathrm{O}$ & 0.9 & 1.6 \\
\hline $\mathrm{K}_{2} \mathrm{O}$ & 14.1 & 12.8 \\
\hline $\mathrm{Li}_{2} \mathrm{O}$ & 0.04 & 0.09 \\
\hline $\mathrm{Fe}_{2} \mathrm{O}_{3}$ & 3.7 & 3.4 \\
\hline $\mathrm{CaO}$ & 7.2 & 7.8 \\
\hline $\mathrm{MgO}$ & 6.3 & 6.7 \\
\hline $\mathrm{TiO}_{2}$ & 0.5 & 0.5 \\
\hline $\mathrm{SO}_{3}$ & 4.7 & 5.0 \\
\hline $\mathrm{P}_{2} \mathrm{O}_{5}$ & 4.3 & 4.6 \\
\hline $\mathrm{SiO}_{2}$ & 49.3 & 50.7 \\
\hline $\mathrm{Al}_{2} \mathrm{O}_{3}$ & 5.3 & 5.4 \\
\hline Loss On Ignition, \% & 92.4 & 94.0 \\
\hline \multicolumn{3}{|l|}{ Slagging Potential } \\
\hline silica ratio * & 74.3 & 73.9 \\
\hline Base/acid ratio ** & 0.58 & 0.57 \\
\hline
\end{tabular}

\subsubsection{Air emissions properties}

Effects on potential air emissions measured during the co-firing tests were all beneficial. The offset in $\mathrm{CO}_{2}$ emissions, not including the computations necessary for the feedstock supply and soil sequestration determinations, was simply the percentage of coal heat input displaced. The switchgrass fraction of the fuel is appropriately considered a $\mathrm{CO}_{2}-$ neutral fuel. That is, the $\mathrm{CO}_{2}$ produced during combustion is presumed to be consumed by the growing plants in a closed cycle. (Again, this neglects other complex enterpriseinclusive carbon balance factors.) The amount of $\mathrm{SO}_{2}$ reduction was likewise directly proportional to the percentage of switchgrass burned. This is attributable to the very low sulfur composition of the switchgrass compared to the coal, as seen in Table 6.

The effect on NOx emissions was by far the most complex change in emissions associated with the co-firing tests. The results for NOx emissions are presented in Figure 18. 


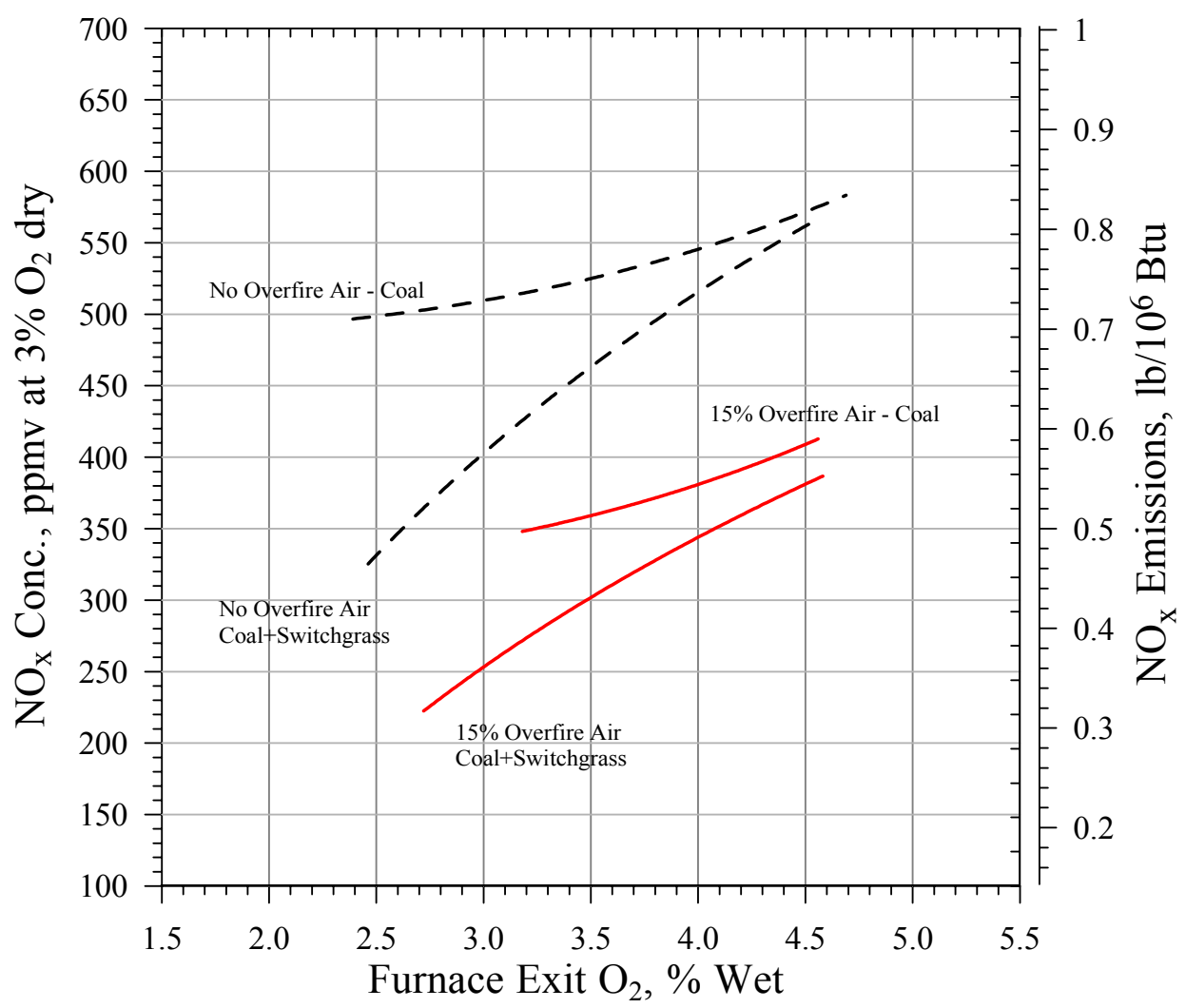

Figure 18. NOx concentrations measured when firing Pratt Seam coal alone and with a co-milled blend of $90 \%$ coal and $10 \%$ switchgrass (mass basis).

These data are with the Pratt Seam coal only and with a blend of nominally $10 \%$ switchgrass and $90 \%$ coal (on a mass basis). The lines in the figure are fitted curves to multiple sets of gas composition measurements. The NOx concentrations are plotted versus the $\mathrm{O}_{2}$ concentration at the exit of the radiant section of the furnace, since this represents a range of fuel and air operating conditions that might be encountered in steam boiler operations. Results in Figure 18 show a clear reduction of $\mathrm{NO}_{x}$ when switchgrass was used as a fuel component. The reduction at normal furnace conditions of $3.6 \%$ furnace exit $\mathrm{O}_{2}$ is greater than what would be expected from the fuel nitrogen values only. This is evident from the data in Table 8.

The markedly higher $\mathrm{NO}_{x}$ reduction than would be expected from the fuel nitrogen content is, in this case of co-milled fuels, attributed to the volatility of the switchgrass. Fuel volatility has been shown to correlate with concentrations of $\mathrm{NO}_{x}$ produced in cofiring tests (16). The mechanism for this effect is the 'pseudo-staging' that occurs in the flame, where the rapid volatilization of the biomass material creates a fuel-rich zone in which $\mathrm{NO}_{\mathbf{X}}$ formation is suppressed. This is similar to the finding with blends of coals 
having substantially different volatile contents (such as blends of bituminous and Powder River Basin (PRB) coals).

Table 8. Expected and Measured $\mathrm{NO}_{\mathrm{x}}$ Reductions at 3.6\% Furnace Exit $\mathrm{O}_{2}$

\begin{tabular}{|c|c|c|c|c|c|c|}
\hline $\begin{array}{c}\text { Coal } \\
\%\end{array}$ & $\begin{array}{c}\text { Switchgrass } \\
\%\end{array}$ & $\begin{array}{c}\text { As Fired } \\
\text { Measured } \\
\% \text { in Fuel }\end{array}$ & $\begin{array}{c}\text { As Fired } \\
\text { Volatile/Fixed C } \\
\text { Ratio }\end{array}$ & $\begin{array}{c}\text { Predicted } \\
\text { Fuel N Red. } \\
\%\end{array}$ & \multicolumn{2}{|c|}{$\begin{array}{c}\text { Measured Reduction } \\
\text { in NOx emissions, \% } \\
\text { No OFA }\end{array}$} \\
\hline \hline 100 & 0 & 1.63 & 0.40 & 0.0 & 0.0 & 31.3 \\
\hline 90 & 10 & 1.56 & 0.80 & 4.4 & 10.4 & 43.4 \\
\hline 0 & 100 & 0.93 & 4.46 & 43.6 & --- & -- \\
\hline
\end{tabular}

Figure 18 reveals separate slopes in the relationship between $\mathrm{NO}_{\mathrm{x}}$ concentration and furnace excess $\mathrm{O}_{2}$ depending on whether biomass co-firing with co-milled fuels was used. These data show that fuel-air ratios and/or fuel mixing can override the 'pseudostaging' effect. The complex relationship of NOx emissions, fuel composition, and combustion conditions is further revealed in the results from co-firing switchgrass with PRB coal. These results are presented in Figure 19.

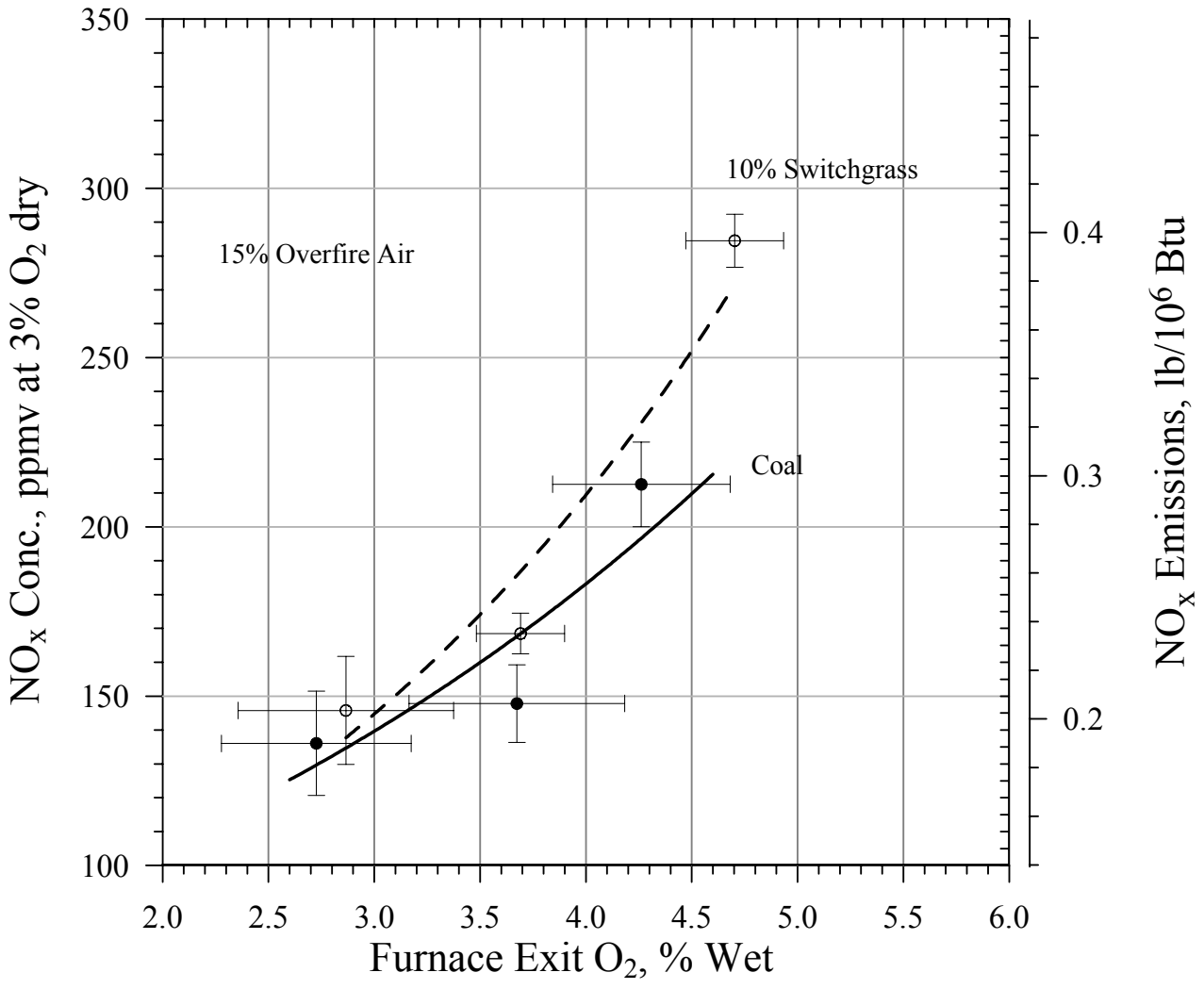

Figure 19. NOx concentrations measured when firing Jacobs's Ranch PRB coal alone and with a blend of $90 \%$ coal and $10 \%$ switchgrass (mass basis). 
The only combustion condition tested was the low-NOx configuration with overfire air. These data show a much lower "inherent" NOx level associated with the PRB than with the Pratt Seam bituminous coal. Furthermore in this case, the addition of switchgrass did not reduce the NOx emissions. In fact, during co-firing there was a small but statistically significant increase in NOx. In all cases with PRB the NOx levels were lower than with the bituminous coal; by over $50 \%$ for the coal only case, and over $40 \%$ for the co-firing case. These data were scrutinized because of the very low levels of NOx reported, and no basis was found to reject these results. (These low levels with PRB coal have since been reproduced on another project, providing more confidence in the results.)

\subsubsection{Carbon burnout}

Conventional staged combustion for NOx control very often results in a decrease in combustion efficiency, evidenced by an increase in unburned carbon in the particulate emissions. For the co-milled coal and switchgrass combination there was, by contrast, a decrease in the unburned carbon content in the ash compared to the coal-only combustion. This is seen in Figure 20.

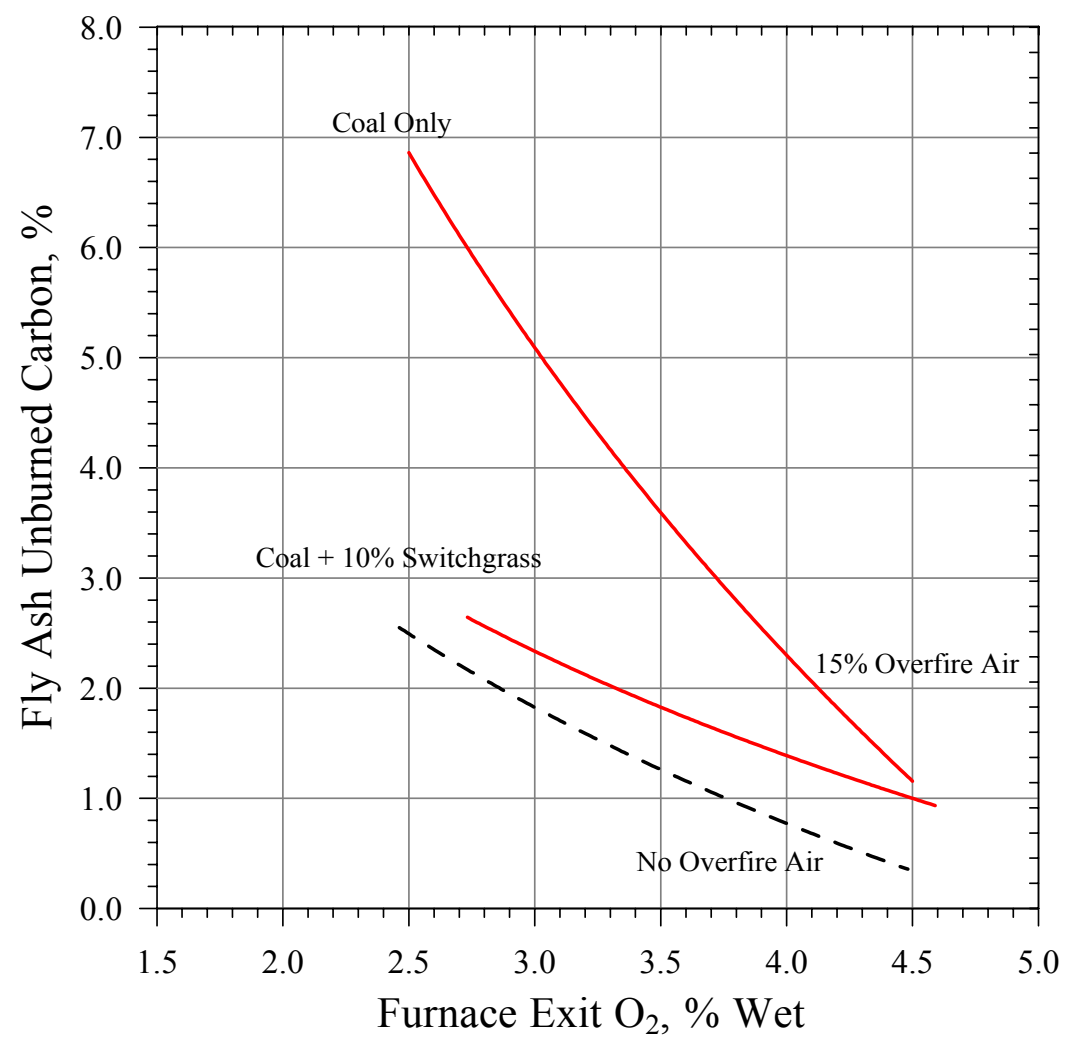

Figure 20. Unburned carbon measured in fly ash after combustion of Pratt Seam bituminous coal and a blend of $90 \%$ coal and $10 \%$ switchgrass (mass basis). 
All of the co-firing tests showed lower unburned carbon for the coal and switchgrass blend cases than for the associated baseline coal cases.

\subsubsection{Direct Injection of Switchgrass}

When it became evident that material handling issues would preclude co-milling switchgrass and coal at Gadsden Steam Plant, we planned a direct injection test for the Combustion Research Facility. The primary objective was to evaluate the degree of burnout or carryover of switchgrass out of the furnace, since the switchgrass would include much larger pieces of switchgrass than had been introduced in the pulverized fuel.

An injection nozzle was built to introduce the switchgrass at the base of the coal flame exiting the primary burner in the combustion facility. Secondary air was diverted from the burner to supply the conveying air for the switchgrass. The total furnace airflow and excess $\mathrm{O}_{2}$ were fixed at levels corresponding to previous testing with co-milled fuel or coal-only fuel. The two-inch diameter switchgrass injection nozzle was angled to intersect the coal flame.

We injected about $400 \mathrm{lbs}$ of switchgrass processed by the Eliminator ${ }^{\mathrm{TM}}$ by Dothan, Inc. to reduce the size to an intermediate level between the field-chopped size and the pulverized size (nominally 0.25 -inches long; much coarser than pulverized coal). An Acrison screw-type feeder delivered the finely chopped switchgrass into the furnace at a metered rate. The injection was observed through viewports in the furnace sections and furnace top. There was near complete burnout of the switchgrass in the lower half of the furnace. No fouling deposits were observed during the test, and the carbon content of fly ash sampled after the heat exchangers did not increase (another evidence of complete carbon burnout).

A small amount of tub ground switchgrass, without any additional size reduction, was also fed into the furnace. This material would not feed through the screw-feeder system, but had to be manually fed into the conveying air. This coarser material persisted in the furnace longer; that is, embers were visible farther up the furnace in this case. However, there was no evidence of any embers persisting to the top of the furnace.

The diverted flame from the angled switchgrass injection nozzle did lead to some deposition on the furnace wall opposite the injection, but this was due to impaction from the airflow and not to any property of the switchgrass. 
Figure 21 shows a summary of results of NOx emissions from coal only, co-milled coal and switchgrass, and the directly-injected switchgrass.

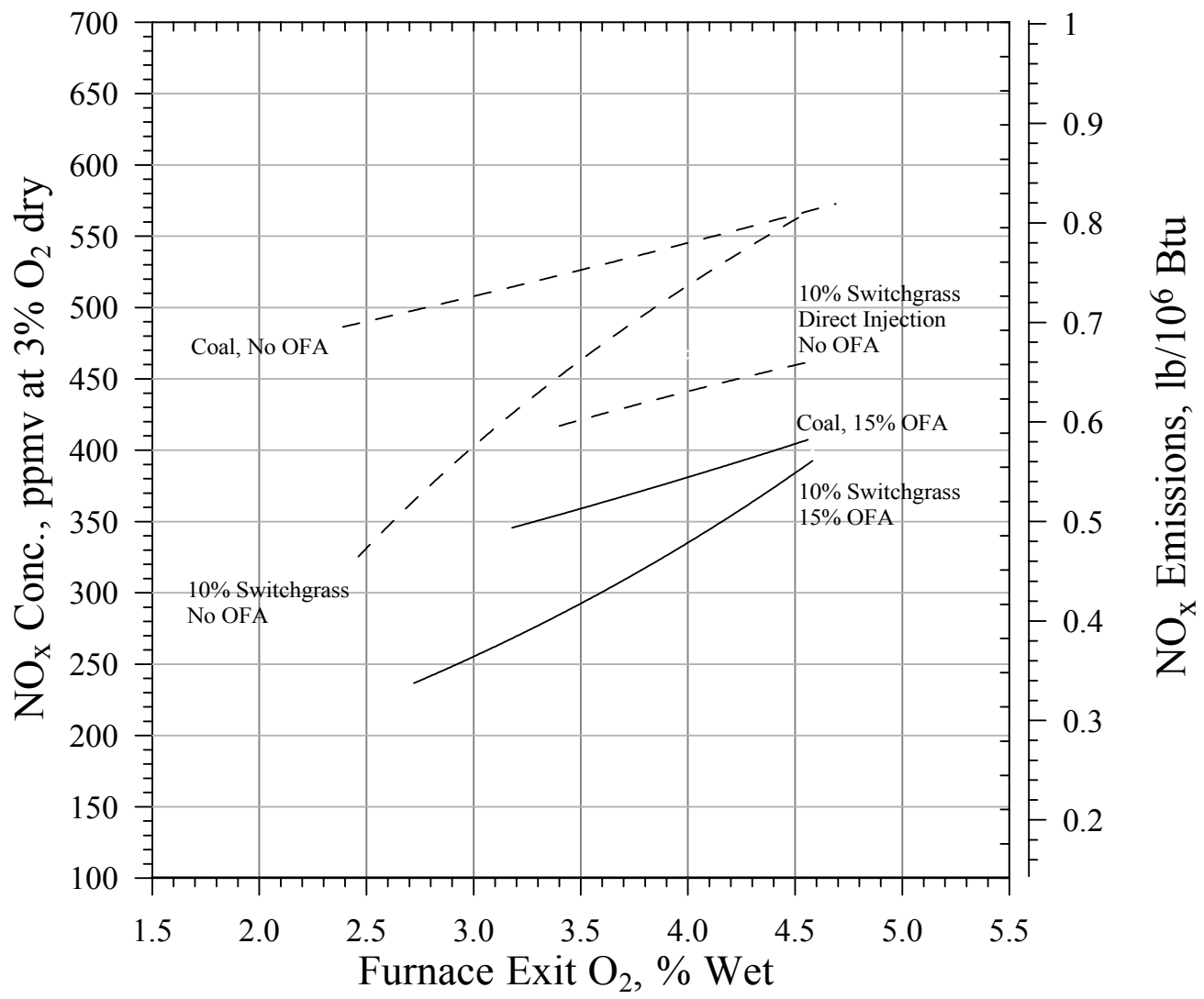

Figure 21. NOx concentrations measured when firing Pratt Seam coal alone, with a blend of $90 \%$ coal and $10 \%$ switchgrass (mass basis), and with direct injection of switchgrass equivalent to $10 \%$ of the fuel (mass basis).

The trend in $\mathrm{NO}_{x}$ concentration from separate injection of switchgrass is in the middle of the values for co-milled switchgrass with and without over-fire air. This limited data set suggests that the direct injection of switchgrass behaved as a form of staging; the slope of the $\mathrm{NO}_{x}$ relationship to furnace excess air is similar to the coal-only cases, with the data indicating an intermediate reduction of $\mathrm{NO}_{x}$. These data reveal a significant dependence of $\mathrm{NO}_{x}$ reduction on injection configuration. 


\subsection{Full-Scale Co-firing Demonstration}

To investigate the potential of switchgrass at full scale, tests were conducted to evaluate some of the benefits and costs associated with co-firing switchgrass in an existing coalfired boiler. A complete discussion of the full-scale demonstration is provided in a separate report (4). A summary is included in the following paragraphs.

\subsubsection{System Design}

The site of the testing was Alabama Power Company's Plant Gadsden, located in Gadsden, Alabama. The plant consists of two essentially identical 70MW Combustion Engineering tangentially-fired pulverized coal units, with Unit 2 selected for testing. The units are typically fueled with eastern bituminous coal. Initial plans were to mix biomass with the coal on the pile, transport it into the plant with the existing coal conveying system, and co-mill coal and switchgrass together in the pulverizers. When laboratory testing indicated that the mix would not properly flow through the coal storage bunkers, the program was revised to test direct injection of switchgrass into the boiler.

Switchgrass was delivered to the plant in large round bales $(\sim 1600 \mathrm{lb} / \mathrm{b}$ ale, approximately 6' diameter x 5' wide). Approximately 1000 bales were received at the plant, and stored at the plant coal pile for the demonstration. Because of space limitations at the plant, the bales were stacked three high and stored uncovered. The bales were stored there from late January 2001 through the end of the test in mid-April.

The system for processing and pneumatically injecting switchgrass into the furnace was designed and built by McBurney Corporation of Atlanta, GA. A schematic diagram of the injection system is shown in Figure 22. Bales were processed at the plant site through a tub grinder operated with two screens, one with $1 / 2$ " and the other with 1 " perforations. These sizes were chosen to produce the finest material possible and maintain a capacity of 5 tons per hour. Switchgrass particles were nearly all less that about 0.5 " to 0.75 " in length. 


\section{Switchgrass}

Bales
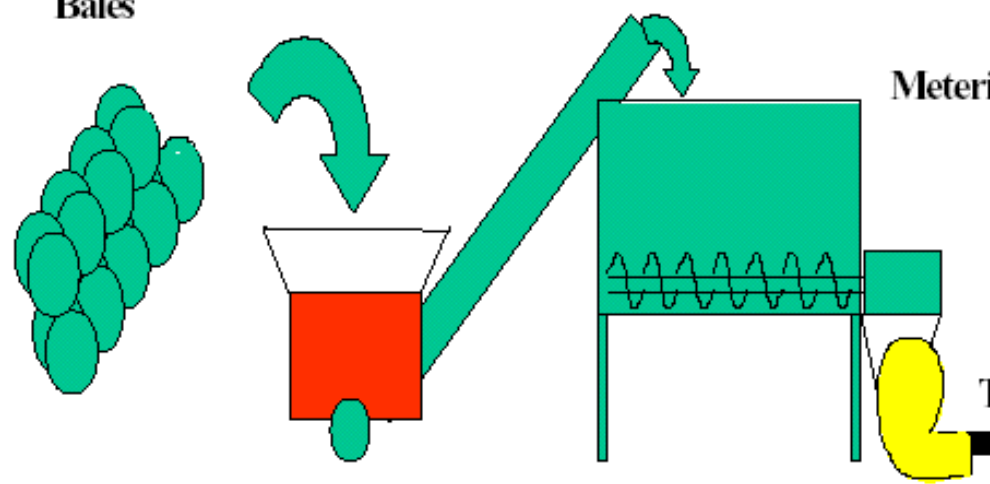

Transport Fan

Tubgrinder

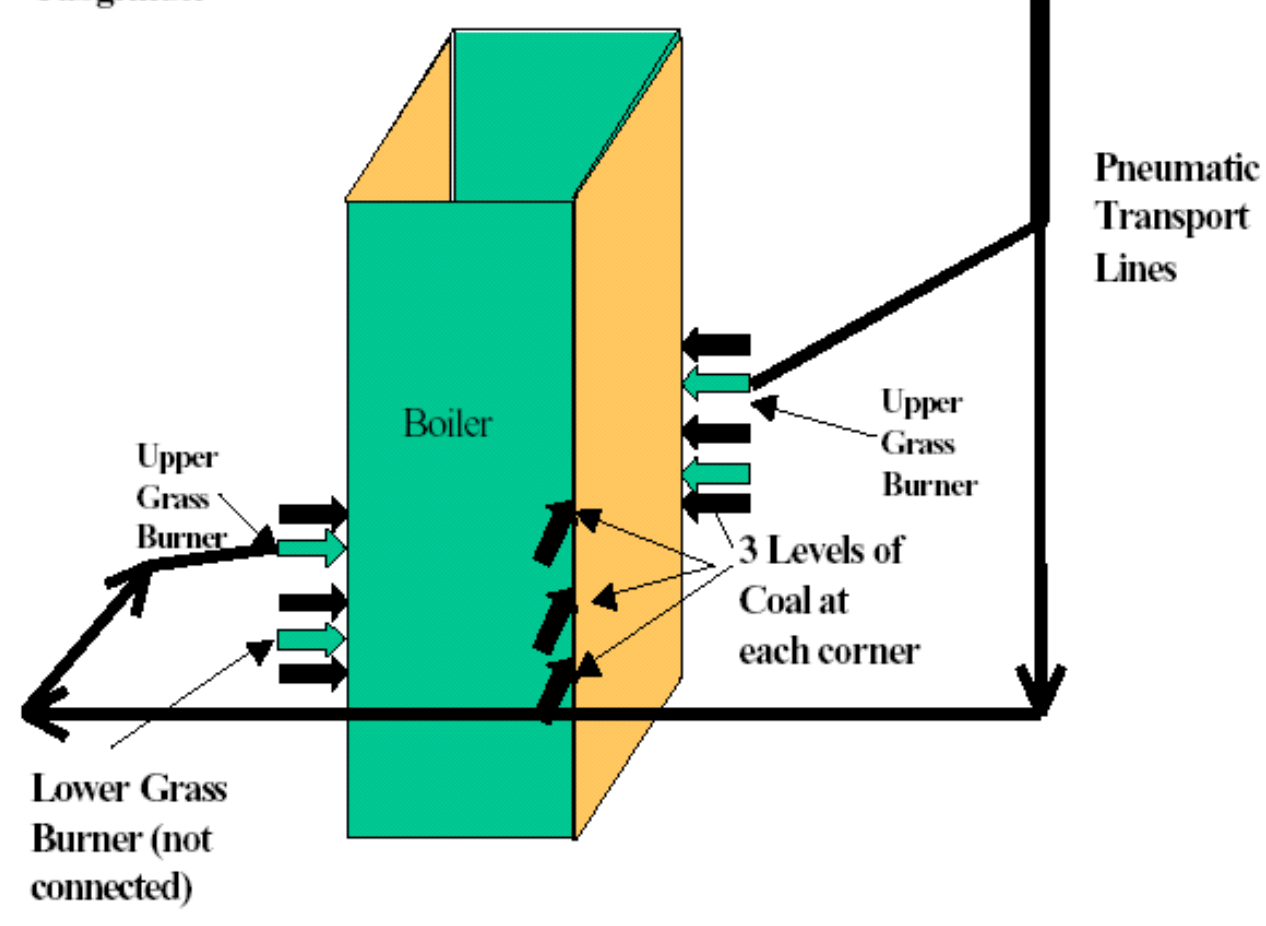

Figure 22. Schematic illustration of the direct injection system at Plant Gadsden.

A metering bin with four chain-driven augers that were turned with a variable frequency drive motor controlled the rate of switchgrass flow to the furnace. The output of the augers was entrained into the intake of a fan which transported the switchgrass to the boiler. Approximately 500 feet of 12 " diameter galvanized steel ducts carried the switchgrass into the power plant. At that point, the transport line divided into two 8" diameter ducts: one of the 8" lines went to a burner on the left front corner of the boiler, and the other 8 " line carried the grass to another burner at the right rear corner of the furnace.

Special grass burners were designed for the project by Foster Wheeler Development Corporation and were installed at diagonally opposite corners of the furnace, and at two 
furnace elevations. Flow to the opposite corners was not balanced (43\% rear, $57 \%$ front).

The unit was instrumented to measure emissions and boiler efficiency, as well as several other operating parameters. During six weeks of testing in March and April of 2001, 40 tests of co-firing were conducted at different operating conditions and percentages of switchgrass. Switchgrass loadings of up to $10 \%$ of the boiler energy input were achieved, with switchgrass input typically at 7 to 8 per cent of the input energy. Figure 23 shows the percentage of coal displaced for various switchgrass feed rates.

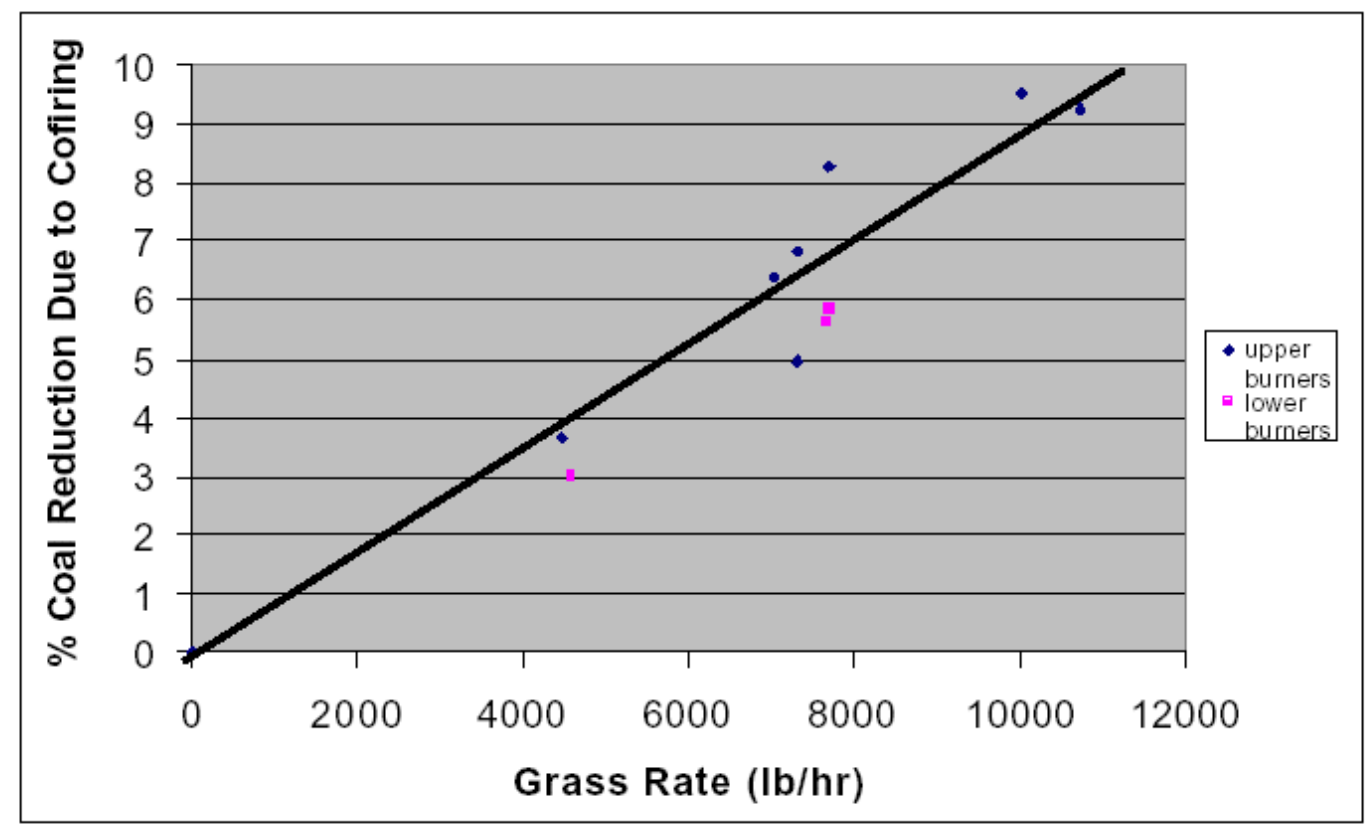

Figure 23. Coal rollback versus switchgrass rate (adjusted for steam flow) at $3 \%$ $\mathrm{O}_{2}$ for upper and lower burners.

\subsubsection{Gas Emissions}

Unit operating data, in particular the coal feed rates to the pulverizers, were used to monitor the "rollback" of coal flow rate when switchgrass was introduced into the furnace. The test conditions, performance data, and associated calculations were therefore referred to as "Rollback". Rollback data were used to characterize emissions, particularly regarding $\mathrm{CO}_{2}, \mathrm{NOx}, \mathrm{SO}_{2}$, and opacity, as well as effective percentage of switchgrass co-firing. In each test for which rollback data were available, the measured parameter, for example opacity or NOx, could be compared directly for coal alone and 
switchgrass co-firing from immediately sequential tests. These rollback data are summarized in Table 9.

Table 9. Rollback Data Summary (Values in table are ratios of Rate with co-firing / Rate with coal alone)

\begin{tabular}{|c|c|c|c|c|}
\hline Test \# & Coal Flow & $\mathrm{SO}_{2}$ & NOx & Opacity \\
\hline 5 & 0.96 & 0.98 & 0.98 & 1.20 \\
\hline 6 & 0.97 & 0.97 & 1.03 & 0.84 \\
\hline 12 & 0.94 & 0.94 & 1.01 & 1.32 \\
\hline 13 & 0.93 & & & \\
\hline 20 & 0.95 & 0.94 & 1.02 & 1.02 \\
\hline 21 & 0.93 & & & \\
\hline 22 & 0.96 & & & \\
\hline 23 & 0.93 & & & \\
\hline 24 & 0.97 & 0.94 & 1.01 & 1.52 \\
\hline 25 & 0.97 & & & \\
\hline 26 & 0.96 & - & 1.00 & 1.09 \\
\hline 27 & 0.96 & & & \\
\hline 28 & 0.95 & & & \\
\hline 29 & 0.92 & 0.99 & 1.18 & \\
\hline 32 & 0.90 & 0.93 & 1.27 & \\
\hline 33 & 0.91 & & & \\
\hline 34 & 0.94 & 0.96 & 0.96 & 1.05 \\
\hline 35 & 0.94 & & & \\
\hline 36 & 0.93 & 0.94 & 0.98 & 1.32 \\
\hline 37 & 0.92 & & & \\
\hline 38 & 0.94 & & & \\
\hline 39 & 0.98 & & & \\
\hline 40 & 0.97 & 0.94 & 1.02 & 1.09 \\
\hline
\end{tabular}

In addition to the emissions data for criteria pollutants shown in Table 9, the net $\mathrm{CO}_{2}$ emissions were reduced equivalent to the fractional coal rate, and mercury was also reduced to the same degree based on the absence of mercury in the switchgrass. $\mathrm{SO}_{2}$ emissions were also measured to decrease with the introduction of switchgrass into the system. Switchgrass had no adverse effect on NOx emissions, but hopes of reducing NOx emissions with co-firing were not realized. With unit load held constant, the rollback 
of coal flow when switchgrass was introduced into the unit was indication of the reduction of fossil carbon dioxide emissions.

\subsubsection{Particulate Control Device Measurements \& Modeling}

Particulate control equipment installed on Gadsden Unit 2 consists of an American Standard electrostatic precipitator (ESP) with three electrical fields in the direction of gas flow (installed in 1949), followed by a Buell ESP with four electrical fields in the direction of gas flow (which was placed in service in 1976). Measurements were made at the inlet and outlet sampling locations of these ESPs during March and April 2001 to characterize the particulate matter and acid gases generated with and without co-firing of switchgrass and to evaluate the particulate collection device under these conditions.

The test program allowed two days of full-load, steady-state operation at two test conditions to complete all measurements. The first test condition was with the boiler firing coal only. The second test condition was with nominally $10 \%$ of the coal displaced by switchgrass directly injected into the boiler as described above. Tests measured mass concentrations across the ESP system on the first day of testing and particle size distributions on the second steady-state day.

Baseline data were obtained on March 9, 12, and 13, 2001. Switchgrass co-firing test data were obtained on March 26 and April 6, 2001. A complete report of these results is included as Appendix $D$ to this report. A summary of the mass concentration results is presented in Table 10.

The particulate collection efficiency of the ESP system during coal-only testing was $99.73 \%$. The inlet mass loading during switchgrass co-firing was $4 \%$ less than the value for the baseline test. The calculated efficiency of the ESP system during co-firing was $99.76 \%$, which is not statistically different than the efficiency of the ESP system during the baseline, coal-only condition. The American Standard ESP collects approximately $80 \%$ of the particulate it receives with the remaining $20 \%$ going to the Buell ESP.

During co-firing the mass median diameter of the fly ash at the ESP inlet was 18.6 microns. This is substantially coarser than the 10.7 $\mu \mathrm{m}$ MMD measured under the baseline case. No outlet size distribution data were obtained during co-firing because the switchgrass injection system was not able to operate at a steady-state condition long enough for the ESP to equilibrate. The inlet size distributions are shown in Figure 24. 
Table 10. Summary of Mass Concentration Measurements

\begin{tabular}{l||c|c||c|c|}
\hline \multicolumn{1}{|l||}{ Test Condition } & \multicolumn{2}{c||}{ BASELINE - COAL } & \multicolumn{2}{c|}{ CO-FIRING } \\
\hline Date & $3 / 12 / 01$ & $3 / 12 / 01$ & $3 / 26 / 01$ & $3 / 26 / 01$ \\
\hline \multicolumn{1}{l|}{ Sample Location } & INLET & OUTLET & INLET & OUTLET \\
\hline $\begin{array}{l}\text { Gas analysis, \% } \\
\mathrm{O}_{2}\end{array}$ & 7.1 & & & \\
\hline $\mathrm{CO}_{2}$ & 11.9 & 11.2 & 12.3 & 12.0 \\
\hline $\mathrm{H}_{2} \mathrm{O}$ & 7.6 & 6.4 & 7.3 & 7.9 \\
\hline $\begin{array}{l}\text { Ambient } \\
\text { pressure, in Hg }\end{array}$ & 29.69 & 29.76 & 30.00 & 30.07 \\
\hline $\begin{array}{l}\text { Static pressure, } \\
\text { in. } \mathrm{H}_{2} \mathrm{O}\end{array}$ & -7.3 & -1.3 & -5.9 & -1.1 \\
\hline $\begin{array}{l}\text { Stack } \\
\text { Temperature, }{ }^{\circ} \mathrm{F}\end{array}$ & 388 & 380 & 393 & 385 \\
\hline Velocity, ft/sec & 36.5 & 56.7 & 33.0 & 48.1 \\
\hline $\begin{array}{l}\text { Gas volume flow, } \\
\text { acfm }\end{array}$ & 394,270 & 374,982 & 355,922 & 318,258 \\
\hline dscfm & 221,168 & 218,608 & 201,936 & 183,462 \\
\hline $\begin{array}{l}\text { Mass loading, } \\
\text { gr/acf }\end{array}$ & 2.56 & 0.0069 & 2.50 & 0.0058 \\
\hline gr/dscf & 4.57 & 0.0118 & 4.41 & 0.0100 \\
\hline mg/acm & 5874 & 15.79 & 5742 & 13.28 \\
\hline mg/dscm & 10471 & 27.08 & 10116 & 23.04 \\
\hline Ib/MBtu & 9.64 & 0.0264 & 9.28 & 0.0220 \\
\hline
\end{tabular}

Chemical analyses of the inlet ash samples indicated that the ash chemistry was essentially the same with and without switchgrass co-firing. There was no appreciable difference in the measured resistivity of the fly ashes produced during the two test conditions. 


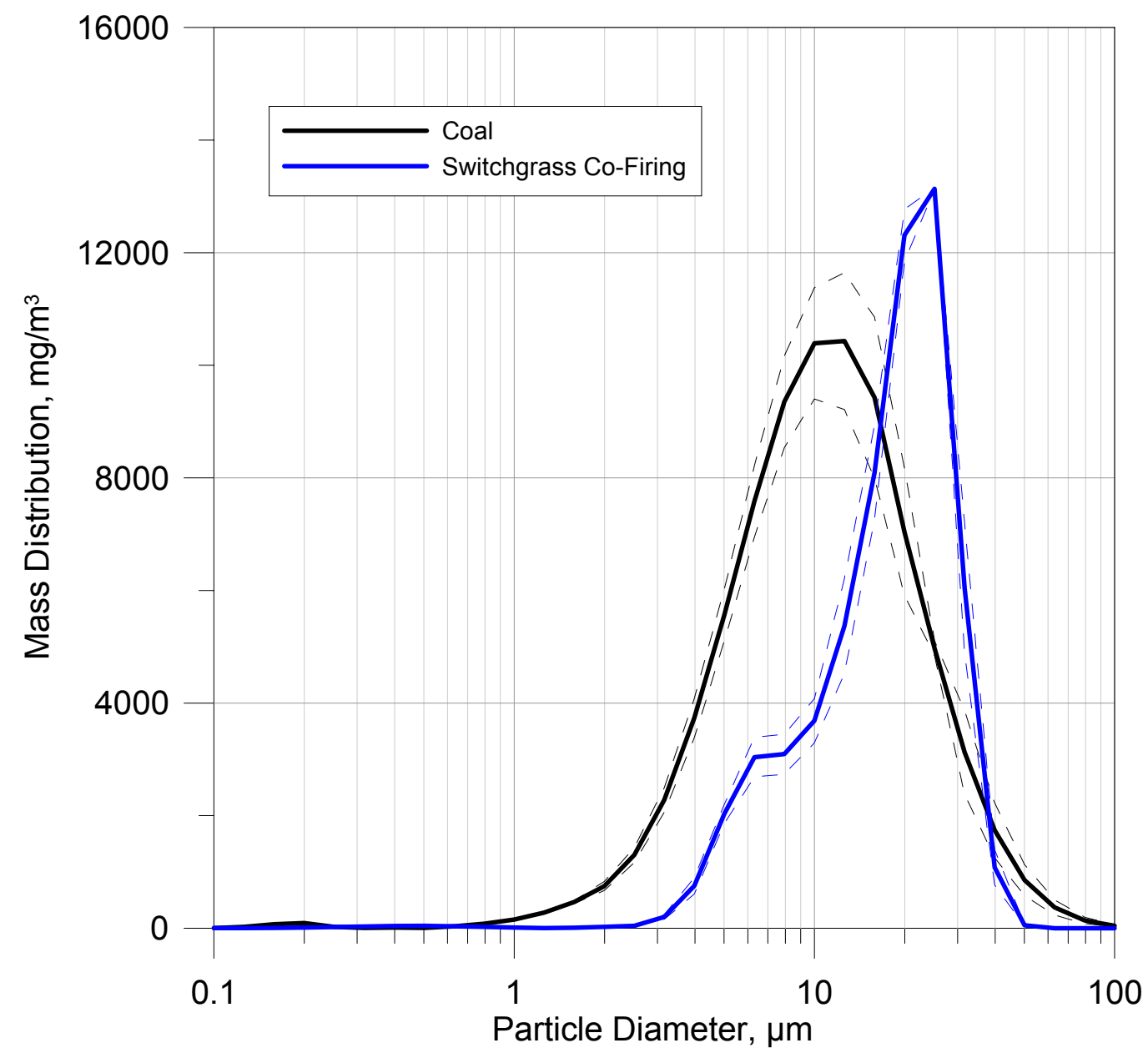

Figure 24. Particle mass distributions at ESP inlet at Plant Gadsden.

The ESP performance measurements were compared to computer model simulations of the ESP system. For the coal-only condition, the model predicted an outlet loading of $0.0296 \mathrm{lb} / \mathrm{MBtu}$ compared to a measured outlet loading of $0.0264 \mathrm{lb} / \mathrm{MBtu}$. The model did not predict as well with switchgrass since the inlet size distribution of the switchgrass particulate was nearly 20 microns. Collection efficiencies are generally greater for size distributions with larger mass median diameters. The gas flow through the ESP's was also less during the switchgrass program and the particulate matter entering the second (Buell) ESP had a larger percentage of carbon, and therefore there was a higher percentage of carbon in the outlet particulate matter. With these qualifications, the ESP model predicted an outlet loading of $0.00445 \mathrm{lb} / \mathrm{MBtu}$ versus the measured loading of $0.022 \mathrm{lb} / \mathrm{MBtu}$. From the results of opacity readings it is likely that enrichment in carbon content in the co-firing cases affected both the modeling accuracy and the apparent optical density of the particulate emissions, even though the outlet mass loading was no greater during co-firing. 


\subsubsection{Boiler Efficiency}

The switchgrass was measured to burn less efficiently than coal. Boiler efficiency penalties of between $0.3 \%$ and $1.0 \%$ efficiency points were measured. Higher dry gas losses with the switchgrass were due to the introduction of quantities of cold air into the furnace with the grass transport system. Switchgrass co-firing also resulted in higher moisture and hydrogen losses. Unburned combustible losses were unexpectedly slightly lower with switchgrass co-firing than for coal alone, offsetting some of the other penalties.

Boiler efficiency with co-firing may be improved by a redesign of the biomass transport system to carry more switchgrass per pound of air, and through modifying the way the switchgrass is stored to reduce losses due to moisture. Heavy rainfall during the period the switchgrass was stored at the coal pile resulted in an average moisture level of $27.7 \%$ and a heating value of $5972 \mathrm{Btu} / \mathrm{lb}$, compared to $10-15 \%$ moisture and 7300 Btu/lb more typical of switchgrass stored under less humid conditions.

Transport and handling caused considerable problems, in large part because the testing was designed to push the system to its physical limits. As a result, data were obtained on requirements to reduce risk of pipe plugging, as well as energy costs for tub grinding and handling the bales. In summary, switchgrass co-firing was tested successfully, and has potential as a renewable energy source. Future efforts will need to focus on reducing fuel costs, improving system efficiencies, and understanding the long-term effects of switchgrass on slagging, fouling, and corrosion in boilers. 


\subsection{CONCLUSIONS}

\subsection{Switchgrass As a Dedicated Feedstock}

Switchgrass proved to be an attractive dedicated feedstock in this project. Our main conclusions from this work include the following:

1) Drought hampered establishment and reduced the rate of progress toward full maturity of the switchgrass stand. However, results from 2001 indicate that a yield of 5.5 tons per acre was achieved with no fertilization, suggesting that 7 tons per acre is a realistic yield to expect from a commercial operation in the southeastern USA, provided moderate levels of fertilizer are applied.

2) From studies of manually harvested switchgrass, the ash content ranged from 2 to $4 \%$ on a dry matter basis, while heat of combustion was mostly around $8,100 \mathrm{BTU} / \mathrm{lb}$, and ash fusion temperature was mostly over $2,000^{\circ} \mathrm{F}$. These factors were influenced very little by switchgrass variety, soil type and level of nitrogen fertilization. Consequently, slagging potential of switchgrass is not as high as might be expected from data reported in other studies.

3) Field chopping proved to be a practically feasible option, and facilitates other options such as cubing and building modules in the field, which will lead to economic advantages in transport when compared to standard round baling and tub grinding. However, this project illustrated that considerable flexibility exists for harvesting, handling, storing and transport of switchgrass, and different options may well suit different regions best.

Perhaps the greatest limitations to large scale deployment of switchgrass as a dedicated energy crop are: a) the need to establish it (as compared to some grasses, such as tall fescue, which are already established on millions of acres ), b) slow and risky establishment, and c) a 3-year delay in attaining full yield. While these limitations are not complete barriers, they do need to be assessed in relation to using existing forage crops which are already established on very large areas, such as tall fescue (Festuca arundinacea; 35 million acres), bahiagrass (Paspalum notatum; 10 million acres), and bermudagrass (Cynodon dactylon; 10 million acres). In addition, many annual crops, such as rye (Secale ceriale) and annual ryegrass (Lolium multiflorum) in winter, and sorgum-sudangrass in summer, could be grown for energy in cropping system rotations with traditional crops, such as cotton, peanuts and soybeans. 
Based on these observations, we feel that future switchgrass research should be focused on reducing risk of establishment, and reducing the time required to reach full yield, in addition to increasing yield in general. However, in view of the current limitations of switchgrass, alternate energy crops and cropping systems also deserve serious research attention, especially if they offer near term advantages over switchgrass.

\subsection{Economic Assessment of Switchgrass Supply}

The economic model developed in this study is an extremely useful research tool. However, it must be emphasized that results derived from the model as reported here relate to the specific values entered into the model. For the examples used in this report, assuming a yield of 6-7 tons/acre, the predicted delivered cost for field-chopped and modularized options ranges between about $\$ 45$ and $\$ 50$ per ton. Again, it must be emphasized that this prediction includes ALL costs, including fixed costs, such as land, labor and equipment. It also assumes the purchase of new equipment which is amortized over 10 years. In addition, it makes no allowance for 'profit' for the farmer.

Although the real cost of switchgrass requires both fixed and variable costs to be taken into account, many farmers already own their land (which therefore incurs no cost in terms of cash payments), prefer to consider the cost of their own time as part of their profit (therefore, not a cash cost), and make use of relatively old tractors and equipment which may already be completely amortized. Clearly, if these issues are considered, costs projected by the model could be reduced.

In support of these assertions is the current situation with the Wilson's switchgrass plantings: they are selling the 5.5 tons/acre of hay harvested in 2001 for $\$ 50 /$ ton on the farm, which obviously includes some 'profit' for them. However, in order to obtain adequate nutritive quality for livestock, two cuts were necessary to ensure the grass was in a relatively immature stage at harvest time, and this would obviously have cost more than a single cut for biomass. Consequently, it is probable that the Wilsons would have been willing to sell biomass from only one cut (as opposed to hay from 2 cuts) at a price of around $\$ 40 /$ ton, and this would still include some profit for them.

Another perspective on this situation is that the Wilsons obtained 5.5 tons/acre without fertilization, and therefore, with no maintenance costs in 2001. Current charges for custom harvesting and baling are about \$20/ton, which would amount to $5.5 \times 20=$ $\$ 110 /$ acre. At a sale price of $\$ 35 /$ ton, gross income per acre would be $\$ 192.50$, and 
income over variable costs would be $\$ 82.50$ /acre, which is competitive with most row crops in the region in most years.

At this point, indications are that it could be entirely feasible to deliver switchgrass to electricity plants at a cost to the utility of around $\$ 45 /$ ton, including 'profit' for the farmer. However, this amounts to $\$ 2.80 /$ million BTU, assuming $8,000 \mathrm{BTU} / \mathrm{lb}$, which is still considerably more expensive than coal. It is clear, therefore, that both further cost reductions and a government subsidy will be necessary to make switchgrass an economically attractive option for both farmers and utilities.

Based on our experience in this project, we feel that high priority in future economic research related to herbaceous energy crops should be assigned to using models such as the one developed here, to conduct sensitivity analyses that will identify the research opportunities which will have the greatest impact on reducing costs. In addition, work needs to be conducted on different options for government subsidies, how much these subsidies will cost, and how best to implement them.

\subsection{Processing and Handling Switchgrass for Fuel}

The major technical impediment to co-firing switchgrass with coal is the difficulty of material handling. The low bulk density and fibrous nature of switchgrass can severely challenge systems designed to move and process coal. We learned that blends of switchgrass and coal would have plugged the coal bunkers at Plant Gadsden even at very low mass concentrations of $5 \%$ switchgrass. This characteristic of the blended fuel would present problems to most power plant fuel storage systems. Additional energy would be required to preprocess the material into either a very fine powder or dense pellets, either of which might have superior material handling properties. There may be applications where the additional processing effort is cost effective, and this should be evaluated further. The economic model developed in this project provides a tool to assist in these evaluations.

The Combustion Research Facility system for fuel handling includes storage hoppers and mechanical conveyers that permitted us to feed and pulverize combinations of coal and switchgrass at up to $20 \%$ switchgrass by mass. Although we did not optimize the milling system for the blended fuel (other than to achieve a fuel fineness specification), the data confirmed that there were large reductions in mill throughput when pulverizing blended switchgrass and coal. More energy was required to achieve a comparable fineness for the composite fuel than for the coal alone. This energy increase was greater for bituminous coal than for Powder River Basin coal. Furthermore, the 
composite fuel had a coarser component made up mainly of switchgrass, whereas the coal component was finer than if milled separately. Thus, the effect of the extra milling energy was to produce a finer coal size distribution. It may be possible to achieve the standard coal fineness (70\% less than 200 mesh) in the presence of the switchgrass with less of a specific grinding energy penalty than we reported. Nevertheless, reduction of mill throughput remains a negative consequence of co-milling switchgrass and coal.

\subsection{Switchgrass Co-firing}

\subsubsection{Pilot-Scale Tests}

Co-firing switchgrass with coal in the Combustion Research Facility resulted in no adverse effects on combustion or emissions. We found no reduction in flame stability, no increase in slagging or fouling, decreases in $\mathrm{SO}_{2}$ emissions, and improved carbon burnout. The effect on NOx emissions was dependent on the baseline coal and whether the switchgrass was co-milled with the coal or directly injected into the furnace. Co-firing at $10 \%$ switchgrass and $90 \%$ bituminous coal (mass basis) led to as much as a $40 \%$ reduction in NOx in the case of co-milled fuel, and a $20 \%$ reduction in the case of direct injection. There was no NOx benefit with the Powder River Basin coal. The pilot-scale testing showed:

- Combustion stability was not degraded by the addition of switchgrass to a coal-fired furnace.

- Slagging and fouling were not increased when the switchgrass was added as a comilled fuel. Deposition in direct injection firing should be studied.

- Environmental performance improved with switchgrass co-firing. $\mathrm{Net} \mathrm{CO}_{2}$ and $\mathrm{SO}_{2}$ decrease proportional to the injection rate of switchgrass, and NOx emissions may be decreased depending on coal, combustion conditions, and degree of fuel mixing.

\subsubsection{Full-Scale Demonstration}

A series of short-term tests co-firing switchgrass with coal was completed at Alabama Power Company's Plant Gadsden. Based on these tests, several conclusions are made:

1. Switchgrass was successfully co-fired with coal at Plant Gadsden. In some tests, up to $10 \%$ of the energy was produced from switchgrass, and in most full-load tests the grass furnished 6 to $8 \%$ of the energy. The system produced between 4 and $4.5 \mathrm{MW}$ of renewable energy at its highest sustainable rate of switchgrass addition.

2. Boiler efficiency for full-load switchgrass co-firing was measured to be approximately $0.3 \%$ to $1.0 \%$ less efficient than for coal-alone firing. Efficiency for switchgrass co- 
firing was lower due to higher dry gas losses associated with introducing cold transport air into the furnace. Additional losses were associated with higher hydrogen and moisture losses (the switchgrass had a very high moisture level of $>27 \%$ due to heavy rains on exposed and stacked bales). In these tests, unburned combustible losses with switchgrass co-firing were unexpectedly lower than for coalalone operation.

3. Emissions of sulfur dioxide and mercury were lower with switchgrass co-firing than with coal-alone operation.

4. Measurements indicated that the slightly higher opacity with switchgrass co-firing is not due to higher particulate emissions. The higher carbon content of the fine material is believed to be responsible for the indicated opacity increase.

5. No change in NOx emissions was measured comparing switchgrass co-firing with coal-alone operation. This is consistent with tests conducted at another power plant. However, the result is disappointing compared with NOx reductions seen in pilot combustor tests conducted for this study.

6. Bales can be stored out of doors if they are not stacked. Stacked bales retain water, significantly increasing moisture content, which results in handling problems, fuel degradation, and increased boiler losses.

7. A tub grinder worked well for processing the baled material to size for combustion. It was forgiving of foreign material, and did not require removal of the bale twine.

Good results were obtained in the short-term tests described in this report. However, questions remain regarding the long-term effects of switchgrass co-firing. To resolve questions for long-term commercial operations, future efforts should involve the following:

- Determine the long-term effect of switchgrass co-firing on slagging and fouling. Analysis of the switchgrass shows the ash to contain high percentages of alkali metal, especially potassium, which could be a problem for fouling back pass tubes.

- Determine if the system or operating procedures can be modified to reduce NOx.

- Conduct tests co-firing other biomass materials such as green and dry sawdust, other grasses, agricultural wastes, and tree-trimming waste to compare the handling, emissions, and performance of different types of biomass in the existing system. Learning how different fuels behave could help in optimizing or at least better understanding the behavior of each, and help to determine the effectiveness of alternative biomass sources for renewable energy production. 


\subsection{REFERENCES}

1. Bransby, D.I. and S.E. Sladden. The need and potential to further raise switchgrass yields based on 10 years of research in Alabama. pp. 253-260. Proc. 2nd Biomass Conf. of the Americas, Aug. 21-24, 1995. Portland, OR.

2. Walsh, M.E., The Cost of Producing Switchgrass As a Dedicated Energy Crop, Oak Ridge National Laboratory, June 1994.

3. Smith, H. Arlen, C. Robert Taylor, and David I. Bransby. Cost of Producing, Harvesting, and Delivering Switchgrass as a Biomass Power Feedstock: $A$ Spreadsheet Model. Agsim Associates, June, 2000.

4. Boylan, D., Bill Zemo, and Jack Eastis. Switchgrass Co-firing at Alabama Power Company's Plant Gadsden: Final Report. Southern Company, August 30, 2001.

5. Bransby, D. I. Field chopping as an alternative to baling for harvesting and handling switchgrass. Proc. 4th Biomass Conf. Of the Americas, Oakland, CA, Aug. 29 - Sept. 2 1999, Oakland, CA: 325-327.

6. Bransby, D. I., P. V. Bush and D. Boylan. Effects of management factors on energy content and slagging potential of switchgrass. Proc. 4th Biomass Conf.of the Americas, Aug. 29 - Sept 2, 1999, Oakland, CA: 1435-1438.

7. Boylan, D., Vann Bush, David Bransby. Switchgrass Co-firing: Pilot Scale and Field Evaluation. Biomass and Bioenergy, vol 19 \# 6, 2000.

8. Boylan, D., Vann Bush, Steve Wilson, and Bill Zemo. Evaluation of Switchgrass Cofiring for Utility Boiler Applications. Proc. ASME - International Joint Power Generation Conference 2001, New Orleans, LA.

9. Boylan, D., Bill Zemo, Jack Eastis, Vann Bush. Switchgrass co-firing at Plant Gadsden. Prepared for Fifth Biomass Conf. of the Americas, December 17-21, 2001. Orlando, FL (abstract in press).

10. Bransby, D. I. and Doug Boylan. Evaluation of switchgrass as a co-firing fuel in the southeast. Biomass Co-firing Project Review Meeting, June 21-22, 2001, DOENETL.

11. Smith, H. A., D. I. Bransby and C. R. Taylor. An interactive budget model for production, harvesting, handling and delivering switchgrass to an energy plant. Prepared for Fifth Biomass Conf. of the Americas, December 17-21, 2001. Orlando, FL (abstract in press).

12. Boylan, D., Steve Wilson, Bill Zemo, Vann Bush. Switchgrass Co-firing with Coal for Power Generation, Proc. Pittsburgh Coal Conference, 4-7 Dec 2001. Newcastle, NSW, Australia.

13. McLaughlin, S. B.. New switchgrass biofuels program for the Southeast. Proceedings, Ann. Auto. Tech. Dev. Contr. Mtng., Dearborn, Ml, 1992. pp 111-115. 
14. Miles, T. R., T. R. Miles Jr., L. L. Baxter, B. M. Jenkins and L. L. Oden. Alkali slagging problems with biomass fuels. Proceedings, $1^{\text {st }}$ Biomass Conf. of the Americas, Burlington, VT, 1993. pp 406-421.

15. McLaughlin, S. B., R. Samson, D. I. Bransby and A. Wiseloge. Evaluating physical, chemical, and energetic properties of perennial grasses as biofuels. Proceedings, $7^{\text {th }}$ National Bioenergy Conf., Nashville, TN, 1996. pp1-8.

16. Tillman, D., L. Reardon, M. Rollins, and E. Hughes, "Co-firing Wood Waste for $\mathrm{NO}_{\mathrm{X}}$ Control in Cyclone Boilers: Identifying the Mechanisms." Proceedings of the Third Biomass Conference of the Americas, Montreal, Canada, Pergamon-Elsevier, Oxford, 1997, Vol. 1, pp.777-785. 